\title{
Erros em esquemas de demonstração com números complexos ${ }^{1}$
}

\section{Resumo}

\author{
Patrícia Damas Beites ${ }^{2}$ \\ ORCID: 0000-0003-0266-7055 \\ Maria Luísa Branco² \\ ORCID: 0000-0002-8589-1310 \\ Cecilia Costa ${ }^{3}$ \\ ORCID: 0000-0002-9962-562X
}

As produções escritas de estudantes podem ser objeto de análise com vista à investigação e ao ensino. Neste trabalho, um dos poucos sobre erros e números complexos, analisamse as produções, elaboradas por estudantes do ensino superior, para uma tarefa de demonstração de um caso particular da identidade do paralelogramo. Num trabalho que pode dar pistas para a prática letiva de professores do ensino secundário e do ensino superior, procura-se classificar os esquemas de demonstração nessas produções, identificar os erros neles cometidos e relacionar estas duas vertentes de análise. A natureza da investigação é qualitativa, recorrendo à análise de conteúdo empregando, por um lado, critérios prévios de categorizações de esquemas de demonstração e, por outro, critérios novos de categorizações de erros. Constatou-se que os estudantes utilizaram, principalmente, esquemas de demonstração de convicção externa, incluídos numa subcategoria nova designada por não válidos no universo, e esquemas de demonstração dedutivos, incluídos num nível novo que se caracteriza por discernimento incipiente da compreensão da tarefa, do contexto matemático, de hipóteses e tese, e dos conhecimentos prévios a mobilizar. Os erros dominantes nas produções estão relacionados à compreensão dos conceitos de linearidade de uma função e de módulo de um número complexo, apresentando-se possíveis explicações para os mesmos. Apesar de não se identificar uma relação propriamente significativa entre os esquemas de demonstração produzidos pelos estudantes e os erros cometidos, obteve-se material para construção e discussão de questões conceituais no âmbito do tópico números complexos.

\section{Palavras-chave}

Educação matemática - Esquema de demonstração - Erro - Identidade do paralelogramo - Número complexo.

1- Este trabalho foi apoiado por fundos nacionais por meio da Fundação para a Ciência e a Tecnologia (FCT), no âmbito dos projetos UID/ CED/00194/2019, UID/MAT/00212/2019 e UIDB/00212/2020.

2- Universidade da Beira Interior, Covilhã, Castelo Branco, Portugal. Contatos: pbeites@ubi.pt; Ibranco@ubi.pt

3- Universidade de Trás-os-Montes e Alto Douro, Vila Real, Vila Real, Portugal. Contato: mcosta@utad.pt 


\section{Errors in proof schemes with complex numbers}

\section{Abstract}

The written productions of students can be subjected to analysis for research and teaching purposes. In the present work, one of the few on errors and complex numbers, the productions presented by Higher Education students for a proof task of a particular case of the parallelogram identity are analysed. In a work that may give clues for the teaching practice in High School and Higher Education, we attempt to classify the proof schemes of those productions, to identify the errors and to connect these two strands of analysis. The nature of the research is qualitative, making use of content analysis with, on the one hand, known criteria of categorization of proof schemes and, on the other hand, new criteria of categorization of errors. The students produced, mainly, external conviction proof schemes, included in a new subcategory called not valid in the universe, and deductive proof schemes, included in a new level that is characterized by the inchoate discernment of the comprehension of the task, of the mathematical context, of the hypotheses and thesis, and the previous knowledge that was needed. The dominant errors in the productions, for which possible explanations are presented, are related to the understanding of the concepts of linearity of a function and of modulus of a complex number. Although a significant relation between the proof schemes produced by the students and the errors is not identified, material for the construction and the discussion of concept questions in the context of complex numbers is obtained.

\section{Keywords}

Mathematics education - Proof scheme - Error - Parallelogram identity - Complex number.

\section{Introdução}

A matemática é tradicionalmente apresentada como perfeita e, portanto, sem erros. Embora esta seja a visão da matemática como produto final, a matemática como ciência não resultou só de acertos, mas também de erros (BORASI, 1994). A sua evolução permanente continua sendo desta forma, com a presença de erros cuja identificação é uma oportunidade para refazer raciocínios. Esses erros na atividade de um matemático não devem ser olhados como um fracasso na construção do conhecimento.

Do mesmo modo, os erros na aprendizagem da matemática devem ser vistos como parte integrante e oportunidade de (auto)regulação (GUIMARÃES, 2016), em que são corrigidos aspectos do processo que não são acertos. Como explicam Borasi (1994), Lannin, Barker e Townsend (2007), Pinto (1998) e Rico (1998), trata-se de ver o erro no sentido construtivista, que "pelo processo regulador [...] pode ser fonte de tomada de consciência, levando o sujeito a modificar seus esquemas” (PINTO, 1998, p. 31). 
A referida visão do erro deve ser a mesma para o aluno, pois a matemática exige que ele desenvolva uma aprendizagem autorregulada, dentro e fora da sala de aula, e persista mesmo quando comete erros (GUIMARÃES, 2016). Estes devem levar o professor a repensar sua prática letiva para promover a autorregulação do aluno, constructo que tem sido associado ao sucesso acadêmico (GUIMARÃES, 2016). Contudo, em Portugal, são escassas investigações feitas com alunos do ensino superior no âmbito do erro em matemática.

Este trabalho pretende analisar produções de alunos do ensino superior português para uma proposição com valor lógico verdade, relativa a um caso particular da identidade do paralelogramo. Por meio das representações, busca-se aceder ao raciocínio matemático do aluno nessas produções. Objetiva-se, assim, classificar seus esquemas de demonstração, identificar os erros cometidos, designadamente na compreensão do conceito de número complexo, e relacioná-los com os esquemas.

0 contexto do estudo é o tópico números complexos de uma unidade curricular (uc) de matemática, de uma licenciatura do ensino superior português. Tendo em vista os objetivos descritos, busca-se responder às questões de investigação: que esquemas de demonstração são elaborados pelos alunos para essa tarefa? Quais os erros, nomeadamente os conceituais relativos a número complexo, cometidos pelos alunos nessas produções? Que relações existem entre os esquemas produzidos e os erros presentes?

\section{Enquadramento teórico}

\section{Esquemas de demonstração (EDs)}

A construção da matemática como ciência é suportada pela demonstração, majoritariamente, baseada no método dedutivo. Contudo, mesmo ao nível do ensino superior, a experiência mostra que a demonstração continua a ser uma dificuldade (BUCHBINDER; ZASLAVSKY, 2019; MIYAZAKI; FUJITA; JONES, 2017). Por exemplo, Recio e Godino (2001) mostraram que alunos universitários espanhóis evidenciaram limitações no uso espontâneo de esquemas de demonstração (EDs) dedutivos para demonstrar proposições matemáticas elementares com valor lógico verdade.

Partindo destes pressupostos, adotou-se a perspectiva compreensiva de ensinoaprendizagem da demonstração de Harel e Sowder (1998, 2007), uma vez que esses autores não usam o termo demonstração no sentido matemático, mas sim como aquilo que estabelece a verdade de uma proposição para um certo indivíduo (ou comunidade). Dada uma proposição, esta pode ser considerada uma conjectura ou um fato, dependendo da certeza desse indivíduo sobre sua veracidade. Uma conjectura torna-se fato logo que esse indivíduo a considere verdadeira. Assim, o que para uns pode ser considerado demonstração pode não o ser para outros e, até para os mesmos indivíduos, essa apreciação pode modificar-se ao longo do tempo.

Dado o caráter subjetivo da proposta de Harel e Sowder (1998), a definição do conceito central da sua perspectiva - ED de um indivíduo (ou comunidade) - decorre naturalmente como o que constitui autoconvencimento e persuasão para esse indivíduo (ou comunidade). 0 modo usado pelo indivíduo para eliminar dúvidas sobre a verdade da proposição é 
denominado por esses autores de processo de demonstração, que é constituído por dois subprocessos expectáveis: um de autoconvencimento, relacionado à eliminação das próprias dúvidas; e outro de persuasão, usado na eliminação das dúvidas de outros sobre a verdade da proposição (HAREL; SOWDER, 1998, 2007). Apresenta-se um resumo da proposta, em que um indivíduo pode manter mais de um esquema em simultâneo, na Tabela 1.

Tabela 1 - Classificação de ED

\begin{tabular}{|c|c|c|}
\hline Categorias & Subcategorias & Descrição \\
\hline \multirow{4}{*}{ Convicção externa } & & As conjecturas são validadas recorrendo-se a fatores externos, como: \\
\hline & Autoritário & a autoridade de outro (pessoa ou material) \\
\hline & Ritual & o ritual da argumentação apresentada \\
\hline & Simbólico não referencial & a forma de escrita simbólica da argumentação \\
\hline \multirow{3}{*}{ Empírico } & & As conjecturas são validadas recorrendo-se à experiência \\
\hline & Indutivo & $\begin{array}{l}\text { A argumentação baseia-se num ou mais exemplos, em medições diretas, em } \\
\text { concretizações de variáveis etc. }\end{array}$ \\
\hline & Perceptual & A argumentação baseia-se em percepções (entendimento sensorial) \\
\hline \multirow{3}{*}{ Dedutivo } & & $\begin{array}{l}\text { As conjecturas são validadas em todos os casos (generalidade). A argumentação } \\
\text { é organizada em etapas apropriadas para alcançar o objetivo final (pensamento } \\
\text { operacional) e baseada em regras lógicas (inferência lógica) }\end{array}$ \\
\hline & Transformativo & $\begin{array}{l}\text { A argumentação envolve as características de generalidade, pensamento } \\
\text { operacional e inferência lógica (referidas anteriormente) }\end{array}$ \\
\hline & Axiomático & $\begin{array}{l}\text { Acrescenta à anterior o reconhecimento da fundamentação axiomática da teoria } \\
\text { matemática correspondente }\end{array}$ \\
\hline
\end{tabular}

Fonte: Harel e Sowder (1998).

Os estudos de Beites, Branco e Costa (2020), Buchbinder e Zaslavsky (2019), Chazan e Lueke (2009), Healy e Hoyles (2000), Recio e Godino (2001), Rodrigues (2009), entre outros, continuam a evidenciar que os empíricos são os EDs mais utilizados por alunos em diferentes níveis de ensino. Em geral, os alunos observados ficam convencidos de que com um ou alguns exemplos é possível demonstrar a validade de uma proposição e, em contrapartida, apresentam grandes dificuldades na compreensão da prova por contraexemplo.

Ainda que a classificação dos EDs de Harel e Sowder (1998) seja reconhecida e utilizada por muitos investigadores, a relevância e a dificuldade da compreensão da aprendizagem da demonstração continuam a estimular novos estudos. É o caso de Lee (2016), que estabeleceu graus mais finos de progressão nos EDs dos alunos para proposições matemáticas com valor lógico verdade. Como se descreve na Tabela 2, o autor considerou quatro fases subdivididas em dois níveis cada, com exceção à primeira fase. Lee (2016) considera que a classificação de Harel e Sowder pressupõe que a demonstração matemática progride de uma orientação indutiva para uma orientação dedutiva, ideia com a qual parece não concordar. Além disso, o autor também acredita que faltava a percepção de certas subtilezas cognitivas manifestadas pelos alunos nos EDs que apresentavam. 
Tabela 2 - Classificação de ED para proposições matemáticas com valor lógico verdade

\begin{tabular}{|c|c|c|}
\hline Fases & Níveis & Características \\
\hline $\begin{array}{l}\text { 1. Tentativas que falharam em relacionar } 0 \\
\text { antecedente e o consequente }\end{array}$ & 0 & Envolvimento irrelevante ou mínimo em inferências \\
\hline \multirow{2}{*}{$\begin{array}{l}\text { 2. EDs baseados em exemplos ou erros de } \\
\text { raciocínio lógico }\end{array}$} & 1 & Uso incipiente de exemplos ou de raciocínio lógico \\
\hline & 2 & $\begin{array}{l}\text { Uso estratégico de exemplos para raciocinar ("experiência crucial") ou de } \\
\text { inferências produtivas }\end{array}$ \\
\hline \multirow{2}{*}{$\begin{array}{l}\text { 3. EDs baseados em inferências dedutivas } \\
\text { incompletas }\end{array}$} & 3 & $\begin{array}{l}\text { Uso de inferências dedutivas com grandes falhas na coerência lógica e } \\
\text { validade }\end{array}$ \\
\hline & 4 & $\begin{array}{l}\text { Uso de inferências dedutivas com falhas menores na coerência lógica e } \\
\text { validade }\end{array}$ \\
\hline \multirow{2}{*}{$\begin{array}{l}\text { 4. EDs baseados em inferências dedutivas } \\
\text { coerentes }\end{array}$} & 5 & Construção de provas dedutivas informais \\
\hline & 6 & Construção de provas dedutivas usando representações formais \\
\hline
\end{tabular}

Fonte: Lee (2016).

Comparando as duas propostas de classificação, observa-se que as duas primeiras categorias de Harel e Sowder $(1998,2007)$ são idênticas às duas primeiras fases de Lee (2016). Os dois níveis da segunda fase contribuem para uma operacionalização mais fácil da segunda categoria de Harel e Sowder (1998). Esse contributo de Lee (2016) para a operacionalização da classificação de Harel e Sowder $(1998,2007)$ é mais efetivo em relação à terceira categoria, ao subdividi-la em duas fases e estas em dois níveis cada. Com o estudo de Kanellos, Nardi e Biza (2018), surge mais uma contribuição para refinar a perspectiva de Harel e Sowder (1998, 2007). Com alunos do ensino não superior, esses autores não só encontraram evidências de seis dos sete EDs propostos por Harel e Sowder (1998, 2007), mas também oito combinações desses seis esquemas. Recentemente, foram encontradas, no ensino superior, três dessas combinações, ainda dos níveis propostos por Lee (2016), e uma nova - ED dedutivo, transformativo, nível 5, com um exemplo que o confirma (BEITES; BRANCO; COSTA, 2020).

\section{Erro}

Segundo Rico (1998), erro é qualquer conhecimento detectado que seja deficiente e incompleto, evidenciando uma dificuldade (PINTO, 1998). Neste sentido, a compreensão das dificuldades do aluno passa pela identificação dos seus erros no processo de ensino-aprendizagem. 0 erro pode ser encarado de várias formas, mas Lannin, Barker e Townsend (2007) propõem que o erro seja encarado como veículo da aprendizagem. Essa posição tem crescido na educação matemática, marcando a passagem de uma visão condutivista (avaliação do erro como produto) para uma visão construtivista (avaliação do erro como processo).

A descrição dos efeitos do erro por Torre (1993) abrange este olhar: destrutivo e deturpador, construtivo e criativo. Os dois primeiros dizem respeito à forma negativa, na qual o erro é um resultado que provoca falhas irreversíveis. Os dois últimos referem-se à forma positiva, na qual o erro é um processo, podendo constituir um instrumento de 
melhoria e de criatividade. Esta não reside no erro, "mas nas pessoas que são capazes de gerar novas ideias apoiando-se nele" (TORRE, 1993, p. 15). Desse modo, no processo de ensino-aprendizagem, o erro tem grande valor pedagógico e pode constituir uma estratégia didática (PINTO, 1998).

Pinto (1998, p. 110) salienta que “o erro precisa ser um 'observável' para o aluno”, porém não o será “se, antes, não for um 'observável' para o professor”. Para identificar, analisar e refletir sobre o erro e combater o fracasso acadêmico, Davis e Esposito (1990 apud PINTO, 1998) sugerem uma investigação a ser desenvolvida pelo professor em sala de aula. Após o professor observar o erro, ele precisa de criatividade para torná-lo visível e superável para o aluno, o que não é fácil (PINT0, 1998). De fato, trata-se de uma dupla observação que, no caso do aluno, consiste na tomada de consciência do erro e do seu sentido.

A análise de erros pode, assim, ser uma metodologia de investigação e uma metodologia de ensino (CURY, 2007). Utilizar a primeira para a segunda permite uma análise mais fina do erro, que não é apenas algo a ser corrigido, mas antes trabalhado. A possibilidade de criar uma estratégia didática surge, segundo Pinto (1998), quando se cria um espaço de discussão do erro entre os envolvidos que permita amplificar os saberes acerca do erro e construir um processo bidirecional entre aluno e professor. Um exemplo é a utilização de erros na elaboração de questões conceituais para discussão em ambiente de aprendizagem pelos pares (BEITES; ROMANO, 2014).

Como Pinto (1998), Cury (2007, p. 80) tem como objetivo fazer os alunos refletirem sobre o erro, dando sugestões para o seu uso no ensino, com "intervenções didáticas que desestabilizem as certezas, levando o estudante a um questionamento”. A autora apresenta ainda uma visão da metodologia investigadora associada aos erros, salientando consistir em uma análise de conteúdo, mas, lembrando que, "As respostas dos alunos a questões abertas nem sempre vão pelo mesmo caminho, ou seja, nem sempre têm um mesmo tema; assim, é necessário, praticamente em cada estudo, reinventar os passos” (CURY, 2007, p. 61).

A investigação relativa ao erro na aprendizagem abrange vários ramos da matemática, entre eles: geometria (ARCE; CONEJO; ORTEGA, 2014), análise (CURY, 2007) e álgebra (BARROS; FERNANDES; ARAÚJO, 2016). Do conhecimento das autoras, o estudo de Nordlander e Nordlander (2012) parece ser o único sobre erros e números complexos. Esses autores, a partir dos erros num teste de identificação de números complexos, apresentaram quatro categorias de conceito imagem associado a conceito definição de número complexo: artifício matemático; números 2-dimensionais; extensão simbólica da matemática; e mistério incompreensível.

0 referido teste de identificação, um dos instrumentos de recolha de dados de Nordlander e Nordlander (2012), consistia em decidir se os números numa lista eram ou não números complexos. As conclusões do estudo apresentam uma tendência dos participantes: relacionar os números complexos com números 2-dimensionais, com uma parte real e uma parte imaginária, ou com aqueles que, pelo menos, têm a unidade imaginária i visível. Desse modo, a maioria dos participantes no estudo considerou, por exemplo, que $i$ e $\cos \pi+i \sin \pi$ são números complexos, mas que $-2,5$ e $\cos \pi+\sin \pi$ não são. 


\section{Metodologia}

A investigação, de natureza qualitativa, realizou-se numa unidade curricular de matemática do primeiro ano de uma licenciatura cujo programa inclui números complexos. 0 tópico foi abordado como revisão, pois constava no programa do ensino secundário que os alunos frequentaram. Durante o semestre, foram propostas tarefas que envolveram a elaboração de demonstrações. Neste trabalho, o foco foi uma tarefa de avaliação relacionada com o tópico supracitado (Figura 1).

Figura 1 - Tarefa

Sejam $z, w \in \mathbb{C}$. Mostre que se $|z|=|w|$ então $|z+w|^{2}+|z-w|^{2}=4|z|^{2}$

Fonte: Dados do estudo.

A tarefa não foi proposta nem resolvida nas aulas, não constando no material de estudo recomendado. Nas aulas do tópico foram trabalhadas: as demonstrações de comutatividades da adição e da multiplicação de números complexos, com apresentação pela professora e colaboração dos alunos passo a passo; e para qualquer $z \in \mathbb{C},|z|^{2}=z \bar{z}$, com resolução (tentativa) em pequeno grupo de alunos e discussão em grande grupo na correção (dependendo do turno, pelos alunos ou pela professora).

Para analisar as produções dos 57 alunos na tarefa, recorreu-se à análise de conteúdo que, segundo Andréu Abela (1998 apud ARCE; CONEJO; ORTEGA, 2014), é uma técnica de interpretação de textos que permite conhecer melhor diversos aspectos e fenômenos. Em seguida, seguiu-se para as etapas essenciais da análise de conteúdo: "a pré-análise; a exploração do material; o tratamento dos resultados; a inferência; e a interpretação" (BARDIN, 2016, p. 121).

Na pré-análise, o material foi organizado mediante leitura flutuante, tendo a seleção de documentos, a formulação de questões e os objetivos da análise como pontos de partida (CURY, 2007). Foram descartadas doze produções em branco e duas só com o enunciado (sem desenvolvimento). Desse modo, o corpus (conjunto das produções trabalhadas após a pré-análise) é formado por 43 produções, referenciadas com A1, A2, ..., A43, nas quais constam as anotações da professora.

$\mathrm{Na}$ exploração do material, realizou-se um estudo aprofundado do corpus, recorrendo a procedimentos de unitarização e de categorização (CURY, 2007). Na unitarização, o material foi relido para definir as unidades de análise (produções), em que cada uma foi separada do corpus para se realizar as categorizações. Na unitarização e na categorização já se elaborou uma interpretação dos dados, pois a criação de categorias exige o estabelecimento de critérios.

0 primeiro agrupamento seguiu critérios de categorizações de $E D$ (HAREL; SOWDER, 1998, 2007; LEE, 2016) com abertura para eventuais combinações destes (KANELLOS; NARDI; BIZA, 2018). Para o segundo agrupamento, relativo aos erros, uma produção 
correta foi separada das outras 42, parcial ou totalmente, incorretas. Estabeleceram-se critérios na criação indutiva de categorias e aplicação dedutiva destas, "compreendendo o que têm em comum e como podem ser reagrupadas” as unidades (CURY, 2007, p. 64).

No tratamento de resultados, para cada categoria e com vista à compreensão do seu significado, a descrição da categoria foi apresentada por meio de um texto síntese e exemplos, extraídos do corpus, representantes da categoria. Como explica Moraes (1999 apud CURY, 2007), a compreensão mais profunda é alcançada com a inferência, que provém do tratamento de resultados (BARDIN, 2016), e com a interpretação, incluindo a busca de possíveis explicações para os erros.

\section{Desenvolvimento}

\section{Resultados relativos a esquemas de demonstração}

A análise das 43 produções dos alunos permitiu constatar que todos tiveram em conta a hipótese, ainda que a maioria a tenha interpretado de forma incorreta (subsecção "Erros do tipo EM"). Apenas um aluno (Figura 2) partiu da tese e, por equivalência lógica (cometendo erros), obteve a hipótese.

Figura 2 - Produção A32

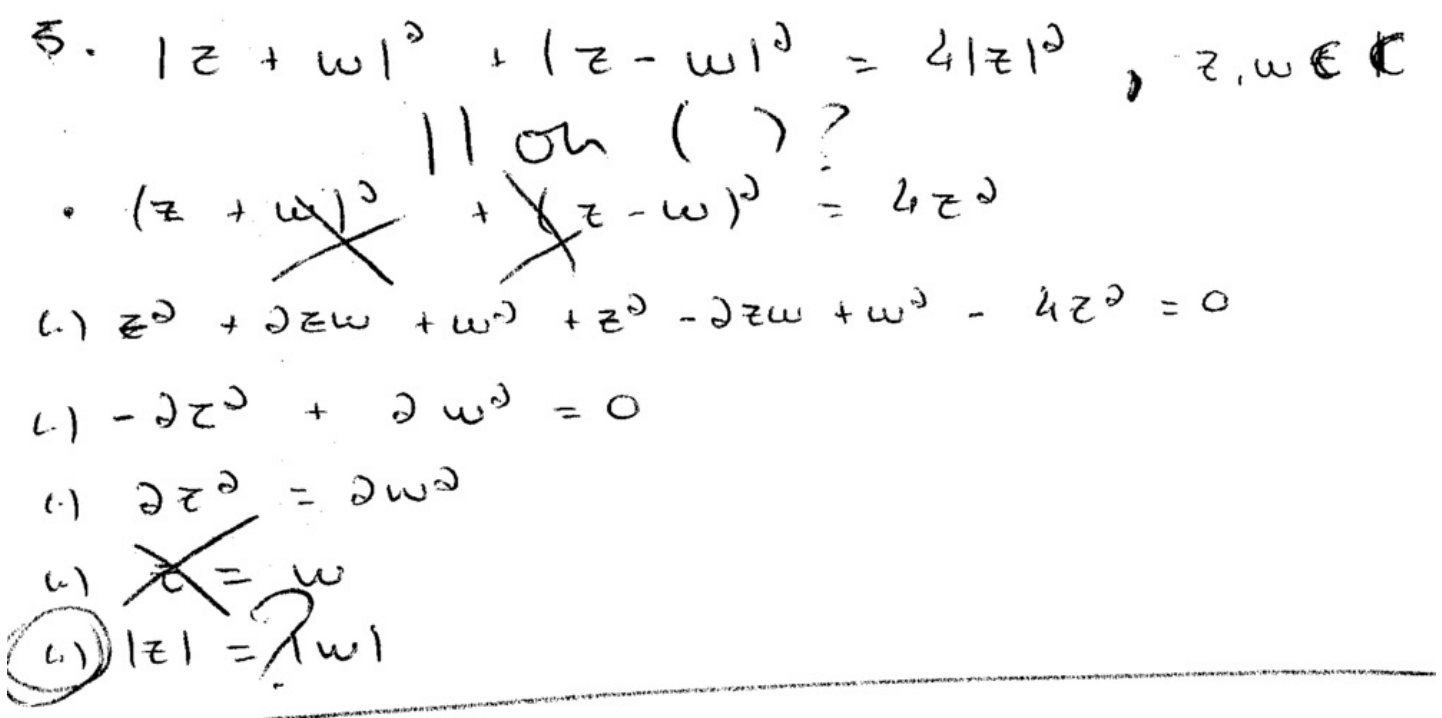

Fonte: Dados do estudo.

Observou-se ainda que 23 alunos (53 por cento) mantiveram $z$ e $w$ para representar dois números complexos quaisquer e os demais escreveram $z$ e $w$ na forma algébrica. Em seguida, os estudantes usaram uma ou mais das seguintes estratégias: transitividade da igualdade; equivalência lógica; cálculo de cada membro e a comparação deles; cálculo de cada parcela do primeiro membro, soma e comparação com o segundo membro; e 
exemplos. Para a contabilização das ocorrências, considerou-se a estratégia utilizada em primeiro lugar. A maioria dos alunos recorreu à transitividade da igualdade (37 por cento) e à equivalência lógica (37 por cento). Cinco alunos efetuaram o cálculo de cada membro e a respectiva comparação. Quatro alunos calcularam separadamente cada parcela do primeiro membro e a sua soma, efetuando em seguida a comparação com o segundo membro. Dois alunos recorreram a exemplos.

$\mathrm{Na}$ Tabela 3 sintetizam-se os resultados obtidos quanto aos EDs, enquadrados nas categorias de Harel e Sowder (1998), na primeira coluna, e nas quatro fases de Lee (2016), na segunda, detalhadas na secção “Esquemas de demonstração (ED)”. Na terceira coluna, apresenta-se a descrição dos aspectos que caracterizam as produções dos alunos e permitem o enquadramento na categoria e na fase das colunas anteriores.

Tabela 3 - Distribuição dos EDs

\begin{tabular}{|c|c|c|c|c|}
\hline Harel e Sowder (1998) & \multicolumn{2}{|l|}{ Lee (2016) } & \multicolumn{2}{|l|}{ Estudo } \\
\hline Categorias & Fases & Níveis & Descrição & $\begin{array}{c}\mathrm{N}^{0} \text { de } \\
\text { ocorrências }\end{array}$ \\
\hline \multirow{3}{*}{ Convicção externa } & \multirow{3}{*}{$\begin{array}{l}\text { 1. Tentativas que falharam em } \\
\text { relacionar } 0 \text { antecedente e } 0 \\
\text { consequente }\end{array}$} & \multirow{3}{*}{0} & Tentativas incipientes de resolução & 6 \\
\hline & & & $\begin{array}{l}\text { Recurso a argumentos de convicção externa } \\
\text { ligados ao simbólico não referencial }\end{array}$ & 4 \\
\hline & & & $\begin{array}{c}\text { Recurso a argumentos de convicção externa não } \\
\text { válidos no universo }\end{array}$ & 13 \\
\hline \multirow[b]{2}{*}{ Empírico } & \multirow{2}{*}{$\begin{array}{l}\text { 2. EDs baseados em exemplos } \\
\text { ou erros de raciocínio lógico }\end{array}$} & 1 & Uso incipiente de exemplos & 2 \\
\hline & & 2 & $\begin{array}{l}\text { Uso estratégico de exemplos para raciocinar } \\
\text { ("experiência crucial") ou inferências produtivas }\end{array}$ & 0 \\
\hline & \multirow[t]{4}{*}{$\begin{array}{l}\text { 3. EDs baseados em inferências } \\
\text { dedutivas incompletas }\end{array}$} & \multirow[t]{3}{*}{3} & $\begin{array}{l}\text { Confusão entre transitividade da igualdade e } \\
\text { equivalência lógica: } \\
\text { - usa igualdade (em vez de equivalência) entre } \\
\text { igualdades sucessivas } \\
\text { - usa equivalência lógica nas primeiras } \\
\text { inferências e depois passa a usar igualdades } \\
\text { sucessivas } \\
\text { - acrescida do uso incorreto do símbolo "donde" } \\
\text { e perda da igualdade numa das inferências }\end{array}$ & $\begin{array}{l}3 \\
+ \\
1\end{array}$ \\
\hline & & & $\begin{array}{c}\text { Substituição de algumas ocorrências de z ou w } \\
\text { de formas diferentes }\end{array}$ & 3 \\
\hline & & & $\begin{array}{l}\text { Inferências dedutivas incompletas, com mais } \\
\text { de um erro }\end{array}$ & 6 \\
\hline & & 4 & $\begin{array}{l}\text { Inferências dedutivas coerentes, apenas com } \\
\text { um erro }\end{array}$ & 3 \\
\hline & $\begin{array}{l}\text { 4. EDs baseados em inferências } \\
\text { dedutivas coerentes }\end{array}$ & 5 & Construção de provas dedutivas informais & 1 \\
\hline
\end{tabular}

Fonte: Dados do estudo. 


\section{Fase 1}

Vinte alunos (47 por cento) apresentaram EDs que se encontram no nível 0. As produções de seis alunos denotam tentativas incipientes de resolução. Três alunos fizeram uma ou duas inferências, sem concluir a tarefa (Figura 3).

Figura 3 - Produção A3

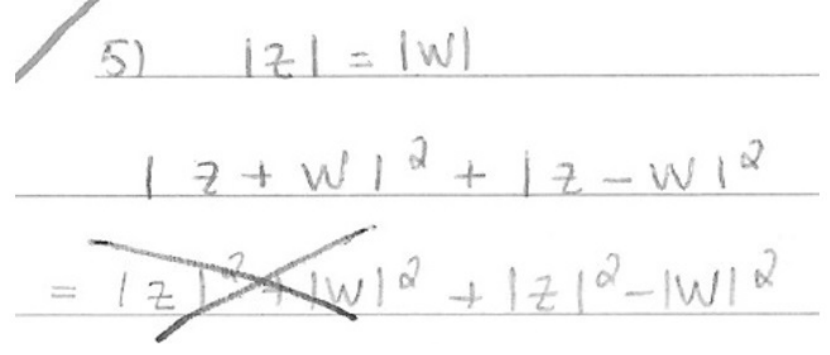

Fonte: Dados do estudo.

Outros três alunos deram a tarefa como concluída, mas efetuando apenas uma ou duas inferências e sem justificações (Figura 4).

Figura 4 - Produção A19

$$
\begin{aligned}
& \text { (5) } \\
& |z|=|\omega| \text { entac }|z+\omega|^{2}+|z-\omega|^{2}=4|z|^{2} \\
& |a+b i|^{x} \times 1 z^{2}-w^{2} V=4|z|^{2}
\end{aligned}
$$

Fonte: Dados do estudo.

Em quatro produções, totalmente erradas, a forma de escrita remete para o recurso a argumentos de convicção externa ligados ao simbólico não referencial, dado o uso de simbologia matemática usada de forma não compreensível (Figura 5).

Figura 5 - Produção A24

$$
\begin{gathered}
\quad|z|^{2}=z^{2} ? \\
\text { 5) }|z|=|\omega|=a+b i \quad z=|z| ? \\
(a+b i)^{2}+(a+b i)^{2}+(a+b i)^{2}-(a+b i)^{2}= \\
=a^{2}+2 a b i+(b i)^{2}+a^{2}+2 a(i+b)^{2}+a^{2}+2 a b i+(b i)^{2}-\left(a^{2}+2 a b i+b i^{2}\right) \\
=a^{2}+2 a b i+b i+a^{2}+2 a b-\not p+a^{2}+2 a b i-b^{2}-a^{2}-2 a b i+b \\
=2 a^{2}+4 a b i-2 b
\end{gathered}
$$

Fonte: Dados do estudo. 
Treze alunos elaboram inferências não válidas no universo da tarefa, assumindo, incorretamente, que as inferências que usaram e eram válidas para $\mathbb{R}$, também eram válidas para $\mathbb{C}$. Menciona-se que esses alunos mantiveram $z$ e $w$ para representar os números complexos. Na produção na Figura 6, representativa de outras oito, se a igualdade definida em $\mathbb{C}$ for esquecida e os traços verticais forem considerados simples parêntesis curvos, as inferências estão corretas, no entanto a validade da dedução lógica falha desde o início, pois os alunos partiram de hipóteses falsas.

Figura 6 - Produção A4

$$
\text { 5. }|z+w|^{2}+|z-w|^{2}=4|z|^{2}
$$

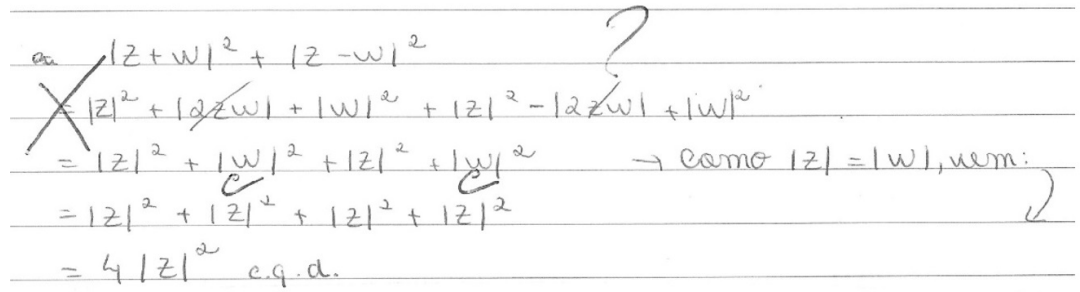

Fonte: Dados do estudo.

A Figura 7 ilustra outro tipo de produções (3) com inferências não válidas no universo da tarefa, visto que os alunos utilizaram propriedades que conhecem em $\mathbb{R}$ e (aparentemente) esqueceram que o contexto da tarefa era $\mathbb{C}$. No caso da Figura 7 , foi usada a proposição $\forall z, w \in I R, z^{2}=w^{2} \Rightarrow|z|=|w|$, noutra produção a proposição utilizada foi $\forall w \in I R,|w|=\sqrt{ } \mathrm{w}^{2}$ representando, em ambas, |:.: $\mid$ o módulo ou valor absoluto de um número real. Na terceira foi usado o caso notável do quadrado da soma de dois números complexos como se fossem reais.

Figura 7 - Produção A11

5. $|z|=|w|$

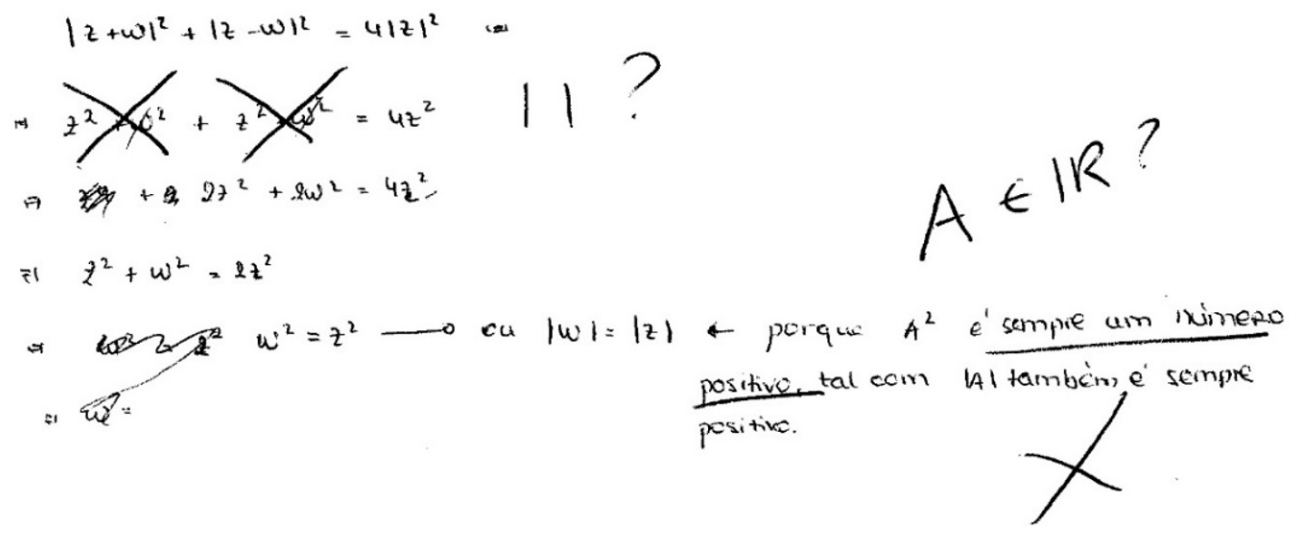

Fonte: Dados do estudo. 
Uma produção apresenta as duas situações referidas. Tendo em conta estas evidências, os EDs desses alunos foram classificados na categoria de convicção externa, numa subcategoria designada não válidos no universo e no nível 0.

\section{Fase 2}

Dois alunos usaram EDs empírico indutivos, nível 0. A produção que apresenta simplesmente um exemplo é a da Figura 8.

Figura 8 - Produção A1

5)

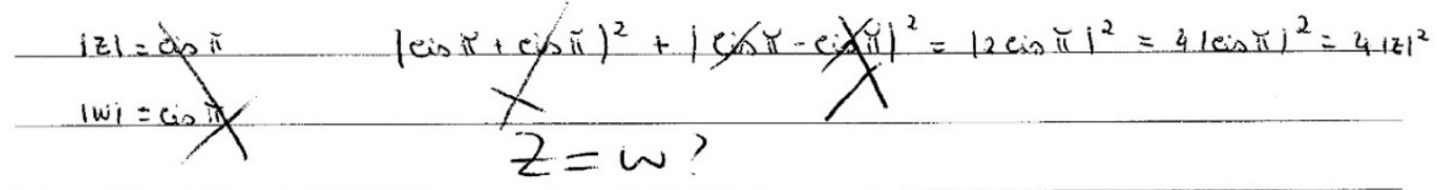

Fonte: Dados do estudo.

Nesses dois casos, os alunos atribuíram valores concretos aos números complexos $Z$ e $w$ e efetuaram os cálculos no sentido de verificar a igualdade. Diferencia-se a produção A14 (Figura 9) por se reconhecer uma fase inicial de intenção dedutiva, usando complexos genéricos na forma algébrica, que, no entanto, não foi levada até ao final, sendo a certa altura introduzida a sua concretização. Nas produções não existe qualquer ocorrência suscetível de ser classificada no nível 2.

Figura 9 - Produção A14

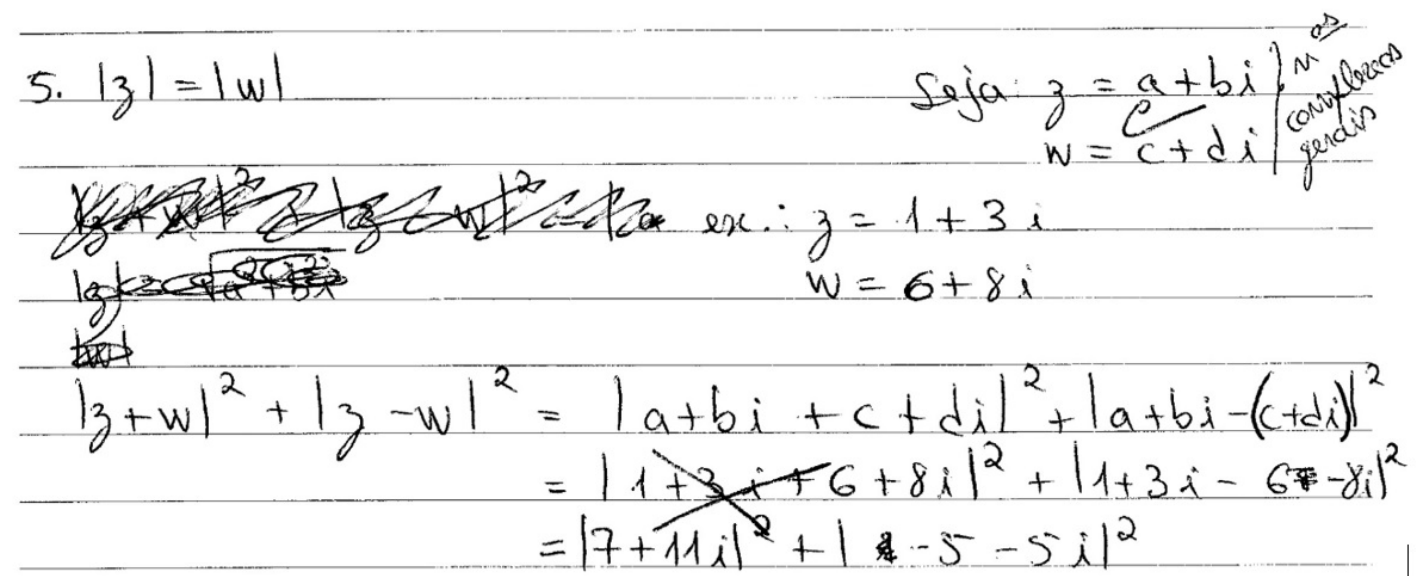

Fonte: Dados do estudo.

\section{Fase 3}

Dezoito alunos (42 por cento) apresentaram EDs dedutivos, distribuídos pelas fases 3 e 4 . 
Na fase 3, nível 3, encontram-se catorze alunos (33 por cento) cujas demonstrações foram baseadas em inferências dedutivas, mas com falhas grandes na coerência lógica e/ou na validade. Cinco alunos confundiram os conceitos de transitividade da igualdade e de equivalência lógica. Um aluno usou a igualdade (e não a equivalência) entre igualdades sucessivas (Figura 10).

Figura 10 - Produção A9

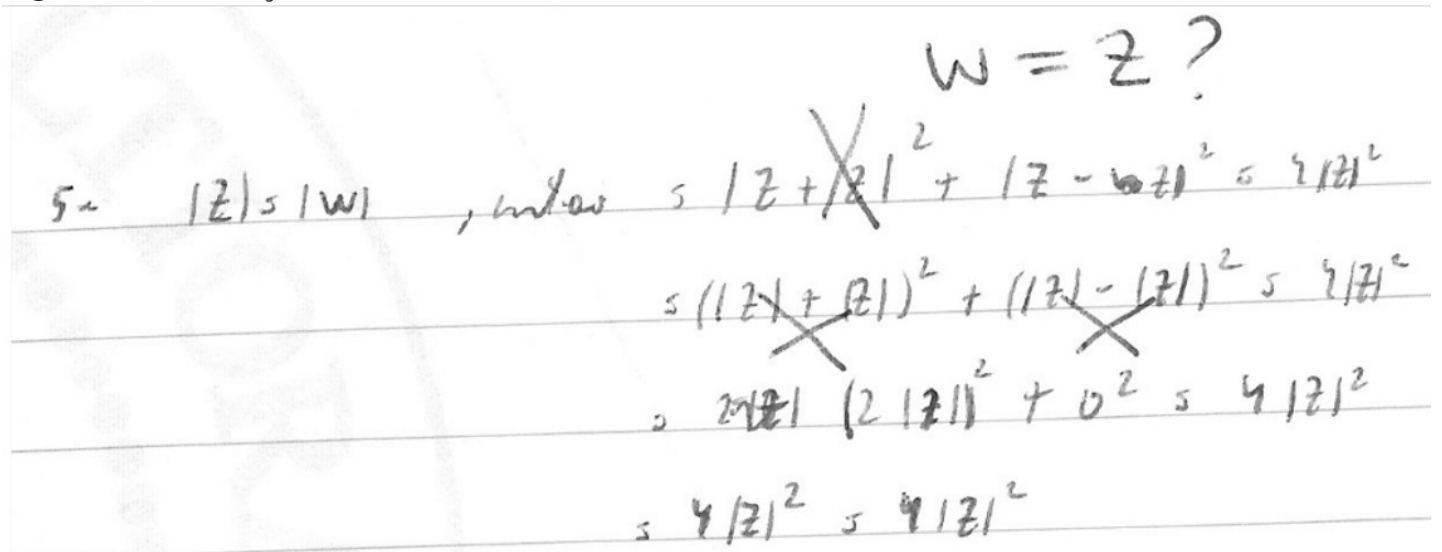

Fonte: Dados do estudo.

Três alunos começaram usando a equivalência lógica nas primeiras inferências e, a certa altura da dedução, empregaram igualdades sucessivas (Figura 11).

Figura 11 - Produção A41

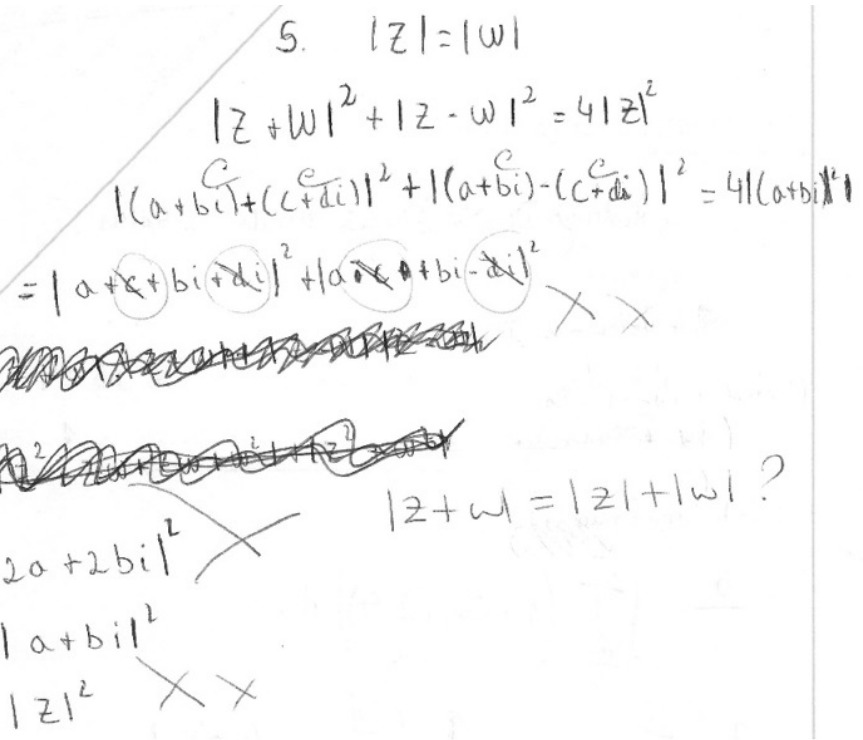

Fonte: Dados do estudo. 
0 terceiro aluno, para além das falhas na dedução lógica anteriormente referidas, utilizou de modo incorreto o símbolo "donde" e não escreveu o segundo membro da primeira igualdade (Figura 12).

Figura 12 - Produção A25

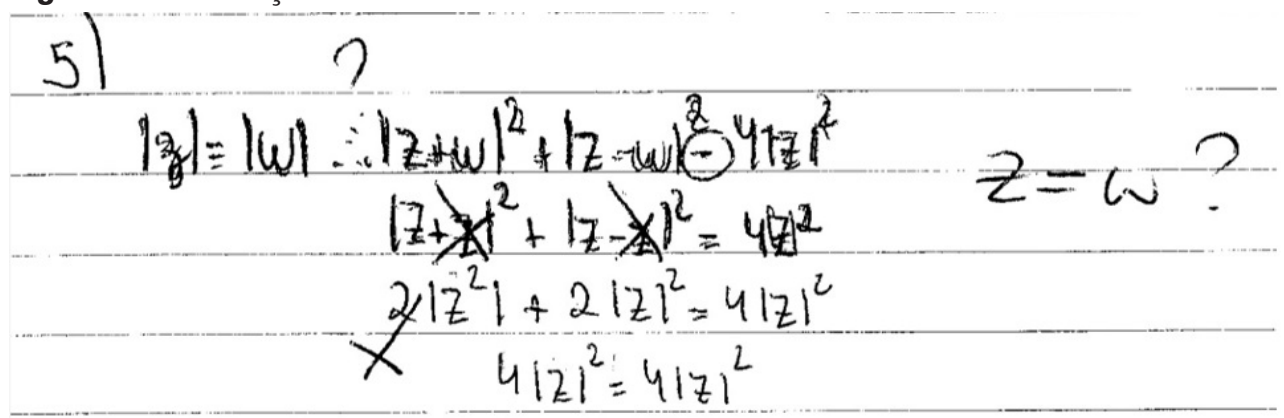

Fonte: Dados do estudo.

Três alunos procederam à substituição de algumas das ocorrências dos números complexos genéricos $z$ e $w$ de formas diferentes (Figura 13).

Figura 13 - Produção A8

$$
\begin{aligned}
& \text { 5. } \left.|z|=|w| \Leftrightarrow\left|a+b_{i}\right|=\left|a_{\mid}\right| b_{i} \mid\right) \quad z=w ? \\
& \left.|z+w|^{2}+\mid z-w\right)^{2}=4|z|^{2} \Leftrightarrow \\
& \left|a+b_{i}+a+b_{i}\right|^{2}+\left|a+b_{i}-a+b_{1}\right|^{2}=4|a+b|^{2} \in
\end{aligned}
$$

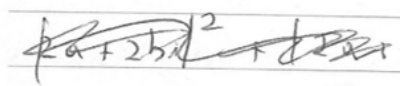

$$
\begin{aligned}
& \left(2++2 b_{1}\right)^{2}+12 a+2 k-\left.w\right|^{2}=4\left|a+b_{i}\right|^{2} \\
& \left(2 a+2 b_{i}\right)^{2}+(z-w)^{2}=4 a^{2}+8 a b i+4 b i^{2} \\
& 4 a^{2}+8 a b i+4(a i)^{2}+\left.|a+5 i-a+| x\right|^{2}=4 a^{2}+8 a b i+4 b i^{2} \\
& 4 a^{2}+8 a b_{i}+4 b_{i}^{2}=4 a^{2}+8 a b_{i}+4 b_{i}^{2} \text { G.a.d }
\end{aligned}
$$

Fonte: Dados do estudo.

Considera-se, ainda, nesse nível um grupo de seis alunos cujas produções apresentaram inferências dedutivas incompletas com mais de um erro (Figura 14). 
Figura 14 - Produção A23

$$
\begin{aligned}
& \text { 5. }|z|=|w| \quad z=4+b_{1} \\
& |z+w|^{2}+|z-w|^{2}=4|z|^{2} \quad \omega=c+d i \\
& \left|a+b_{i}\right|=\left|c+d_{i}\right| \leqslant|a|=|d+| b|=| d \mid
\end{aligned}
$$

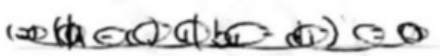

$$
\begin{aligned}
& \left|a+b_{i}\right| \fallingdotseq\left|a+b_{i}\right| \\
& |z+\omega|^{2}+|z-\omega|^{2}=\left|a+b_{i} f c+d i\right|^{2}+\left|a+b_{i} c-c-d i\right|^{2}= \\
& =|a+(+\mid b+d) i|^{2}+|a+c+(b \cdot d) i|^{2}= \\
& =|a+c|^{2}+\left.(b+c) i\right|^{2}+|a-c|^{2}+|| a-\left.\left.d\right|_{i}\right|^{2}= \\
& =a^{2}+t^{2}+b^{2} i^{2}+d^{2} i+a^{2}-\ell^{2}+b^{2} i^{2}-d^{2} i^{2}= \\
& =2 a^{2}+b^{2} \cdot d^{2} \cdot b^{2}+d^{2}= \\
& =2 a^{2}-2 b^{2}=
\end{aligned}
$$

Fonte: Dados do estudo.

Três alunos apresentaram EDs baseados em inferências dedutivas incompletas com falhas menores. Nesses casos há falha no conceito de módulo de um número complexo (Figura 15), razão pela qual são classificados no nível 4.

Figura 15 - Produção A12

$$
\begin{aligned}
& \text { 5. } \quad|z|=|w| ; \quad|z+w|^{2}+|z-w|^{2}=4|z|^{2} \\
& \begin{aligned}
\operatorname{seja} N^{2} z & =a+b i c \\
w & =c+d i
\end{aligned} \\
& \text { mas se }|z|=|w| \\
& \text { entāo }\left|a+b_{i}\right|=\left|a_{y}\right\rangle\left\langle b_{i}\right|
\end{aligned}
$$

Fonte: Dados do estudo.

$$
\begin{aligned}
\text { Comecgmos com } & |z+w|^{2}+|z-w|^{2} \\
= & \left.\left|a+b_{i}+2\right| z b_{i}\right|^{2}+\left|a+b_{i}-a\right|\left\langle\left. b_{i}\right|^{2}\right. \\
& =\left|2 a+2 b_{i}\right|^{2}+|a-a+(b-b) i|^{2} \\
X & \times \\
& =\left|2 a+2 b_{i}\right|^{2} \\
& =4 T a+\left.b_{i}\right|^{2} \\
& =4|z|^{2}
\end{aligned}
$$




\section{Fase 4}

Um aluno efetuou a resolução da tarefa sem erros, usando inferências indutivas coerentes, no entanto ainda usou representações informais na prova dedutiva (Figura 16). $0 E D$ desse aluno foi classificado no nível 5. Nas produções não existe qualquer ocorrência suscetível de ser classificada no nível 6.

Figura 16 - Produção A6

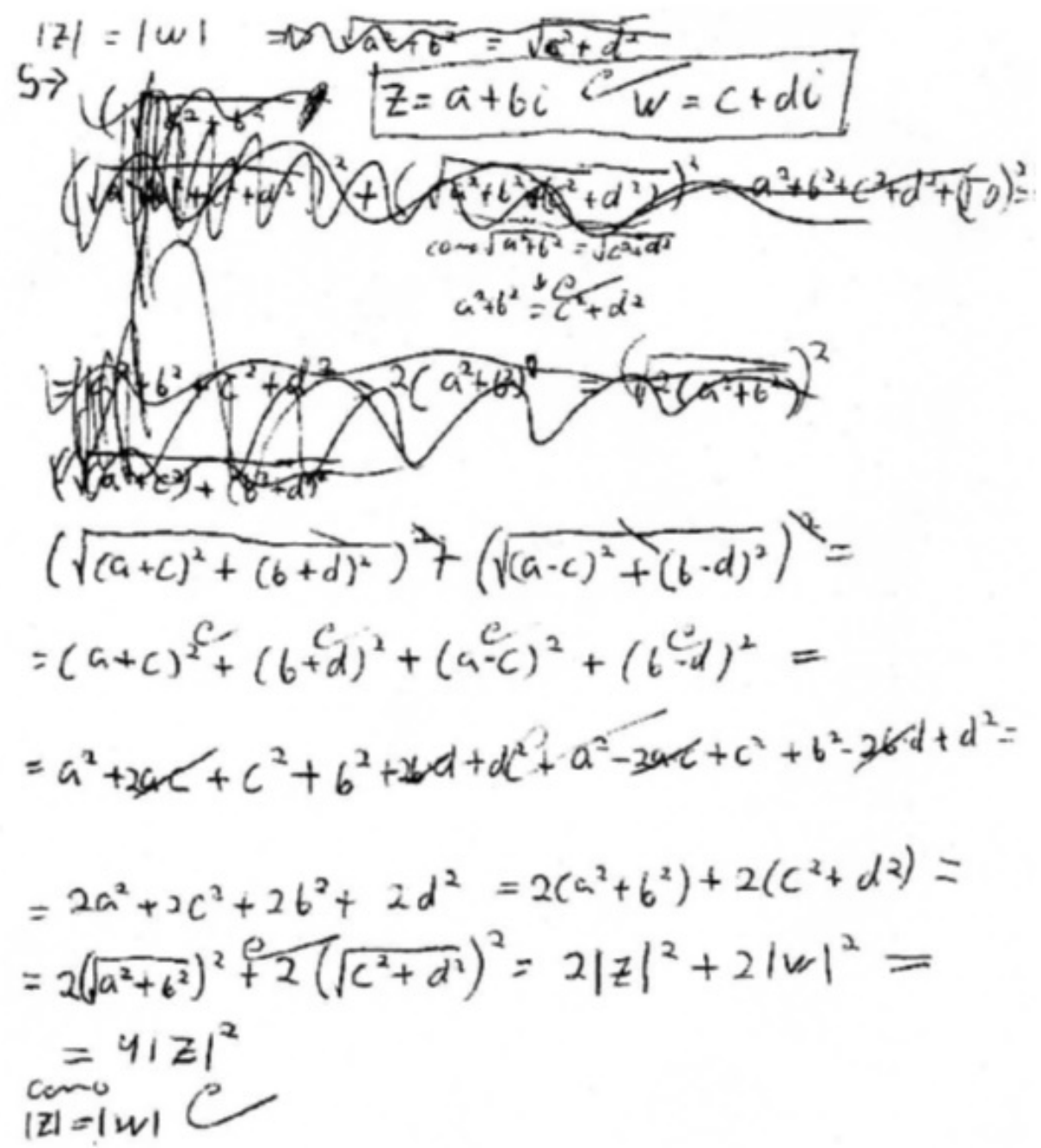

Fonte: Dados do estudo. 


\section{Resultados relativos a erros}

Foram elaboradas categorias para os erros nas produções, cuja distribuição apresentamos na Tabela 4:

EL - erros relacionados à compreensão do conceito de linearidade de uma função;

EM - erros relacionados à compreensão do conceito de módulo de um número complexo;

EA - erros relacionados à aritmética dos números complexos;

ER - erros relacionados à extensão de $\left(\right.$ quase $\left.^{4}\right)$ propriedades dos números reais;

EN - erros relacionados à notação matemática;

ED - erros relacionados à compreensão do conceito de demonstração.

Tabela 4 - Distribuição dos erros

\begin{tabular}{c:c}
\hline Categoria & No $^{\circ}$ ocorrências \\
\hline EL & 36 \\
\hline EM & 34 \\
\hline EA & 20 \\
\hline ER & 17 \\
\hline EN & 17 \\
\hline ED & 11 \\
\hline
\end{tabular}

Fonte: Dados do estudo.

\section{Erros do tipo EL}

Oito alunos consideraram que o módulo da soma de dois números complexos é igual à soma dos módulos desses complexos (Figura 6). Também oito alunos consideraram que o quadrado do módulo da soma de dois números complexos é igual à soma dos quadrados dos módulos desses complexos (Figura 3).

Ainda na Figura 6, encarando a adição e a subtração como duas operações distintas, embora relacionadas, é possivel observar outro erro do tipo EL. Especificamente, cinco alunos consideraram que o módulo da diferença de dois números complexos é igual à diferença dos módulos desses complexos.

Quatro alunos, no desenvolvimento do que poderia passar pelo caso notável quadrado da soma de dois números complexos, consideraram a soma dos quadrados desses complexos (Figura 7). Similarmente, para o quadrado da diferença de dois números complexos, três alunos consideraram a diferença dos quadrados desses complexos.

Outros erros envolvem o quadrado do módulo da diferença de dois números complexos, em que três alunos consideraram a diferença dos quadrados dos módulos desses complexos (Figura 3) e dois alunos consideraram a soma dos quadrados dos módulos desses complexos.

4- 0 vocábulo refere-se à eventual exclusão do número complexo trivial $(0+0 i)$ para a validade de uma propriedade. 
Os erros restantes da categoria são unitários e consistem em: considerar que o módulo da diferença de dois números complexos é igual à soma dos módulos desses complexos; considerar que o quadrado da diferença de dois números complexos é igual à soma dos seus quadrados; e considerar que a raiz quadrada da soma de dois números reais é igual à soma das raízes desses números.

\section{Erros do tipo EM}

Dezenove alunos consideraram a igualdade de números complexos como consequente da igualdade de módulos desses complexos (Figura 17).

Figura 17 - Erro da categoria EM na produção A36

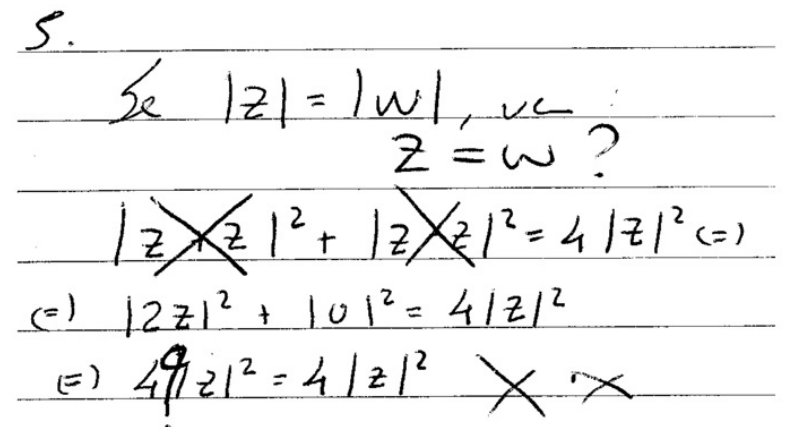

Fonte: Dados do estudo.

Para o módulo de um número complexo, quatro alunos consideraram números complexos, concretos ou representados por expressões gerais, que não pertencem ou que podem não pertencer ao conjunto $\mathbb{R}_{0}^{+}$. Dois exemplos encontram-se na Figura 8 e na Figura 5, esta contemplando números complexos que podem nem ser números reais.

Três alunos consideraram a igualdade de números complexos equivalente à igualdade dos seus módulos (Figura 18). Três erros unitários surgiram da dedução de consequentes a partir da hipótese, em um caso também com uma equivalência: $|z|=|w|=>=-z ;|z|=|w|$ $\Rightarrow|\operatorname{Re}(z)|=|\operatorname{Re}(w)|$ e $|\operatorname{Im}(z)|=|\operatorname{Im}(w)| ;|z|^{2}=|w|^{2} \Longleftrightarrow z=w$.

Figura 18 - Erro da categoria EM na produção A35

Fonte: Dados do estudo.

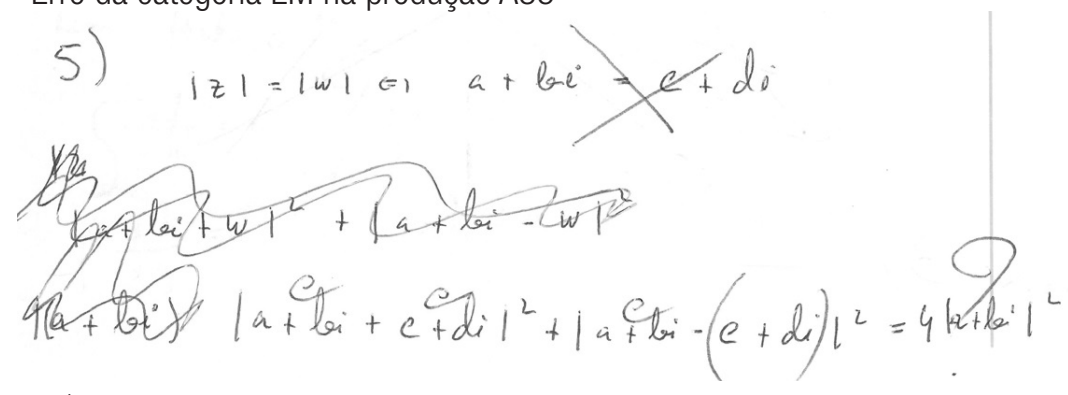


Continuando com os erros unitários na categoria EM, três alunos indicaram expressões com duas parcelas para o módulo e para o quadrado do módulo de um número complexo. Concretamente, escreveram: $|z|=(\operatorname{Re}(z))^{2}+(\operatorname{Im}(z))^{2} ;|z|=(\operatorname{Re}(z))^{2}+\operatorname{Im}(z) \mathrm{i}^{2}$; $|z|^{2}=(\operatorname{Re}(z))^{2}+(\operatorname{Im}(z))^{2}$ i.

Um aluno apresentou duas expressões para os módulos da soma e da diferença de dois números complexos, parecendo encará-los não só como parcelas nessas operações, mas como a parte real e o coeficiente da parte imaginária de algum número complexo: $|z+w|=\sqrt{ }\left(z^{2}+w^{2}\right) ;|z-w|=\sqrt{ }\left(z^{2}-w^{2}\right)$.

\section{Erros do tipo EA}

Cinco alunos efetuaram o quadrado do produto de dois números complexos por meio da multiplicação do primeiro pelo quadrado do segundo (Figura 19). Dois alunos consideraram que o quadrado de um número complexo é igual ao produto do número complexo pelo seu conjugado, parecendo aludir à conhecida propriedade $|z|^{2}=z \bar{z}$.

Figura 19 - Erros das categorias EA e ED na produção A10

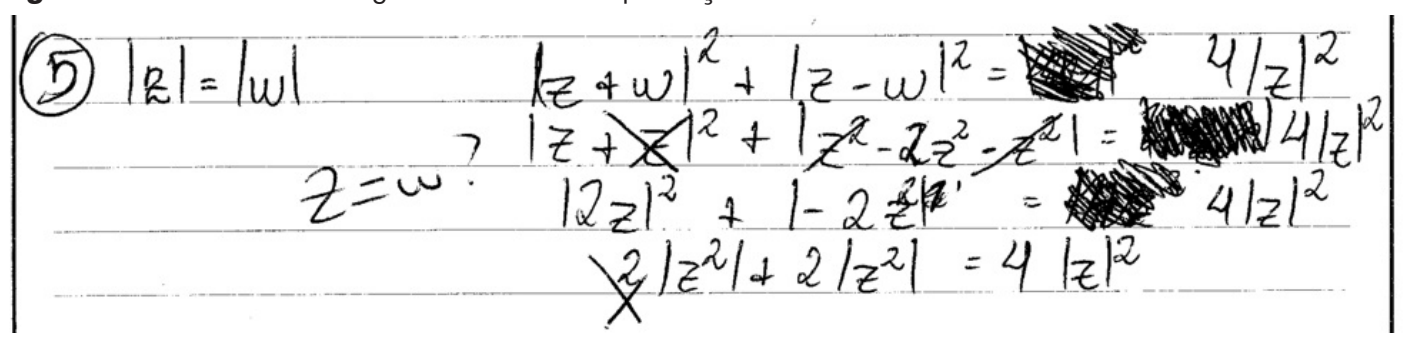

Fonte: Dados do estudo.

Dois alunos consideraram o seguinte desenvolvimento do quadrado da diferença de dois números complexos: $(z-\mathrm{w})^{2}=z^{2}-2 z w-w^{2}$ (Figura 20). Ainda, presencia-se um erro unitário do tipo EA: $|z|^{2}+|z|^{2}=4|z|^{2}$, embora possa ter sido motivado pela observação do segundo membro.

Figura 20 - Erros da categoria EA na produção A7

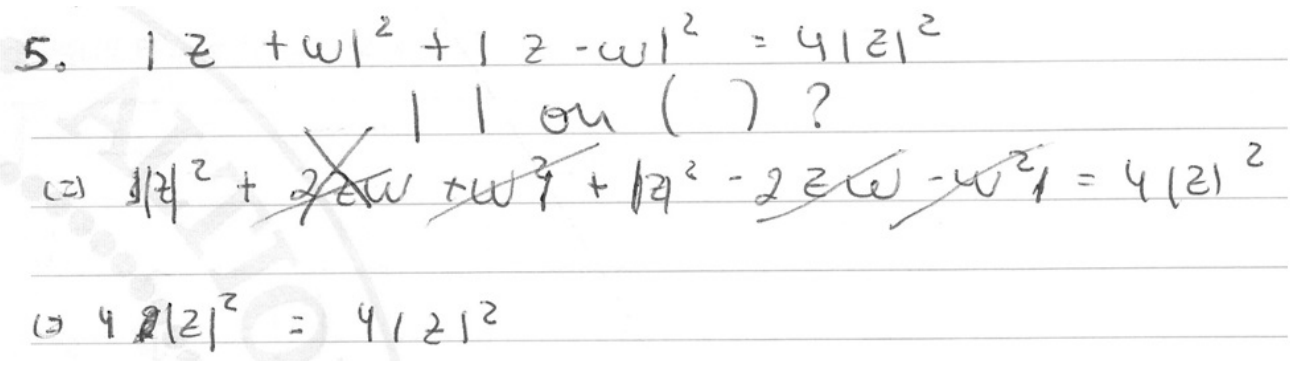

Fonte: Dados do estudo. 
Outros erros aritméticos, e unitários, também são relativos ao desenvolvimento de casos notáveis da multiplicação. Concretamente, três alunos desenvolveram o quadrado da soma de dois números complexos nas seguintes formas: $(2 z+2 \mathrm{w})^{2}=z^{2}+2 z \mathrm{w}+\mathrm{w}^{2}$; $(z+\mathrm{w})^{2}=Z^{2}+2 z \overline{\mathrm{W}}+w^{2} ;(z+\mathrm{W})^{2}=Z^{2}+z w+w^{2}$.

Quatro alunos apresentaram erros unitários relacionados com o quadrado de um número complexo: $-\left(-Z^{2}\right)=-Z^{2} ;-(-z)^{2}=Z^{2} ; \operatorname{bix}(-\mathrm{bi})=(-\mathrm{bi})^{2} ; Z^{2}=w^{2} \Leftrightarrow Z=w ;\left|z^{2}-w^{2}\right|=4|z|^{2}$. Considerou-se a última igualdade, pois, embora o raciocínio não seja visível na produção, coexiste com a escrita da igualdade a provar.

Um aluno cometeu um erro de colocação em evidência de fator comum, relativo à propriedade distributiva da multiplicação quanto à adição de números complexos: $z w+z \mathrm{t}=z(w+z \mathrm{t})$. Também numa ocorrência, um aluno escreveu uma expressão igual à mesma dividida pelo máximo divisor comum dos coeficientes dos termos.

\section{Erros do tipo ER}

Doze alunos consideraram que o quadrado do módulo de um número complexo é igual ao quadrado desse complexo (Figura 7). Dois alunos consideraram que a igualdade dos módulos de dois números complexos é equivalente à igualdade dos quadrados desses complexos (Figura 7).

Apesar de não haver uma relação de ordem em $\mathbb{C}$, a Figura 7 mostra que um aluno considerou positivo o quadrado de um número complexo, bem como o seu módulo. Outro erro unitário na categoria ER consiste em considerar que o módulo de um número complexo é igual às raízes quadradas do quadrado desse complexo (Figura 21).

Figura 21 - Erro da categoria ER na produção A16

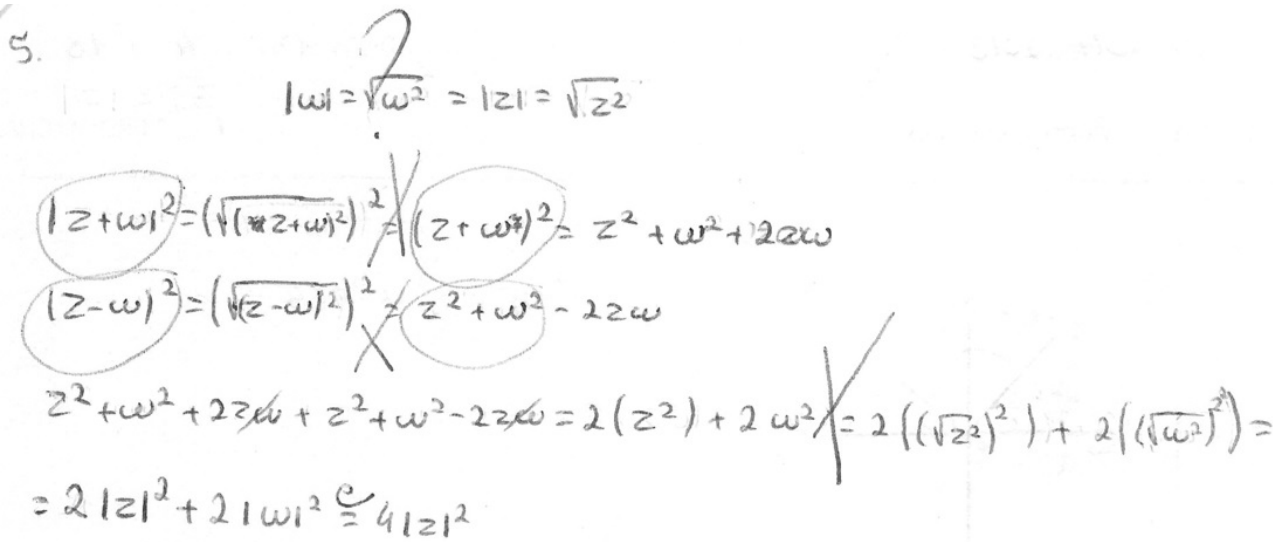

Fonte: Dados do estudo.

\section{Erros do tipo EN}

Os erros da categoria EN não aparecem em toda extensão de cada produção associada, coexistindo com notação correta em situações similares. Cinco alunos escreveram, 
respectivamente, ) ou ( em vez de | ou |. Dois alunos não escreveram pelo menos um dos dois últimos símbolos na expressão a colocar em módulo. Também dois alunos escreveram $-\operatorname{Re}(z)+\operatorname{Im}(z)$ i para representar $-z$.

Registram-se, ainda, erros unitários de oito alunos: escrita de - em vez de $=, \leftrightarrow$ em vez de $\Longleftrightarrow,=$ em vez de $\Longleftrightarrow,+$ em vez de - , "complexos reais" em vez de "complexos iguais"; falta de + na adição efetuada, de expoente 2 no quadrado do produto realizado; e consideração de $z$ e $w$ como números complexos arbitrários e, simultaneamente, concretos.

\section{Erros do tipo ED}

Seis alunos consideraram, implicitamente, implicações sucessivas da igualdade pretendida em vez de equivalências. Desse modo, mesmo não havendo outros erros, não seria possivel obter uma demonstração por equivalência lógica e valor lógico verdade da última igualdade (ex. Figura 19).

Dois alunos consideraram $z$ e $w$ como números complexos concretos, apesar de um deles os tomar inicialmente como números complexos arbitrários. Apresentaram, assim, um caso particular - um dos alunos com testagem completa (Figura 8) e o outro com testagem incompleta da igualdade a provar - em vez de uma demonstração.

Dois alunos escreveram a igualdade a provar igual ao desenvolvimento do primeiro ou do segundo membro da mesma (Figura 11). Logo, assumem implicitamente o que se quer demonstrar, mas sem evidências de incorrer em circularidade lógica.

Um aluno combinou duas formas de demonstração (Figura 22), o que, mesmo sem outros erros, impossibilitaria logicamente a obtenção de uma demonstração. Escreveu uma equivalência em que, concomitantemente, apresentou igualdades sucessivas de uma expressão para chegar ao segundo membro do que queria provar.

Figura 22 - Erro da categoria ED na produção A28

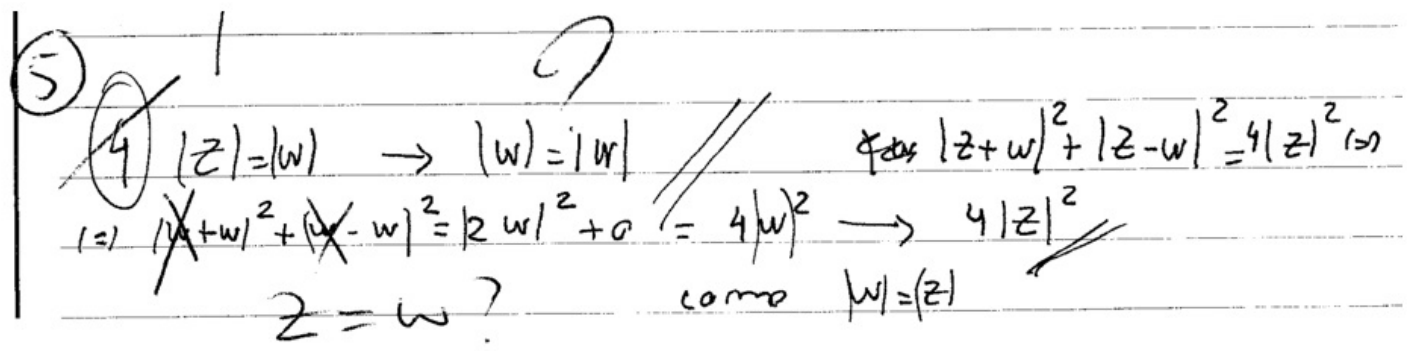

Fonte: Dados do estudo.

\section{Esquemas de demonstração e erros}

Foi organizado na Tabela 5 os EDs, e os erros presentes, nas produções dos alunos.

Nas produções classificadas no nível 0 , consideradas tentativas incipientes de resolução, constata-se a existência cumulativa de erros de tipos diversos (combinações de EL, EM, EA, EN), não revelando a existência de alguma estratégia com vista à demonstração. 
Tabela $\mathbf{5}$ - Distribuição dos EDs e dos erros presentes

\begin{tabular}{|c|c|c|c|c|c|c|c|}
\hline $\begin{array}{l}\text { Níveis de Lee } \\
(2006)\end{array}$ & $\begin{array}{c}\mathrm{N}^{0} \text { de } \\
\text { ocorrências }\end{array}$ & EL & EM & EA & ER & EN & ED \\
\hline \multirow[t]{3}{*}{0} & 6 & $\begin{array}{c}\text { A2 } \\
\text { A3 } \\
\text { A19 } \\
\text { A39 }\end{array}$ & $\begin{array}{l}\text { A26 } \\
\text { A35 }\end{array}$ & A19 & & $\begin{array}{l}\text { A2 } \\
\text { A35 }\end{array}$ & \\
\hline & 4 & $\begin{array}{l}\text { A13 } \\
\text { A24 } \\
\text { A33 }\end{array}$ & $\begin{array}{l}\text { A13 } \\
\text { A24 } \\
\text { A33 } \\
\text { A37 }\end{array}$ & $\begin{array}{l}\text { A24 } \\
\text { A33 } \\
\text { A37 }\end{array}$ & $\begin{array}{l}\text { A13 } \\
\text { A33 } \\
\text { A37 }\end{array}$ & A37 & $\mathrm{A} 13$ \\
\hline & 13 & $\begin{array}{l}\text { A4 } \\
\text { A7 } \\
\text { A11 } \\
\text { A17 } \\
\text { A31 }\end{array}$ & $\begin{array}{l}\text { A5 } \\
\text { A16 } \\
\\
\text { A32 } \\
\text { A34 } \\
\text { A36 } \\
\text { A43 }\end{array}$ & $\begin{array}{l}\text { A7 } \\
\text { A17 }\end{array}$ & $\begin{array}{l}\text { A11 } \\
\text { A16 } \\
\text { A21 } \\
\text { A29 } \\
\text { A32 } \\
\text { A34 }\end{array}$ & $\begin{array}{l}\text { A7 } \\
\text { A17 }\end{array}$ & A31 \\
\hline 1 & 2 & & $\mathrm{~A} 1$ & & & $\begin{array}{l}\text { A1 } \\
\text { A14 }\end{array}$ & $\begin{array}{l}\text { A1 } \\
\text { A14 }\end{array}$ \\
\hline \multirow[t]{3}{*}{3} & 5 & $\begin{array}{c}\text { A9 } \\
\text { A22 } \\
\text { A25 } \\
\text { A41 }\end{array}$ & $\begin{array}{l}\text { A9 } \\
\text { A25 } \\
\text { A28 }\end{array}$ & A22 & & $\begin{array}{c}\text { A9 } \\
\text { A22 } \\
\text { A25 } \\
\text { A28 }\end{array}$ & $\begin{array}{l}\text { A22 } \\
\text { A25 } \\
\text { A28 } \\
\text { A41 }\end{array}$ \\
\hline & 3 & A20 & $\begin{array}{c}\text { A8 } \\
\text { A10 } \\
\text { A20 }\end{array}$ & $\begin{array}{c}\text { A8 } \\
\text { A10 } \\
\text { A20 }\end{array}$ & A8 & A8 & $\begin{array}{l}\text { A8 } \\
\text { A10 }\end{array}$ \\
\hline & 6 & $\begin{array}{l}\text { A18 } \\
\text { A23 } \\
\text { A30 }\end{array}$ & $\begin{array}{l}\text { A18 } \\
\text { A23 } \\
\text { A30 } \\
\text { A38 } \\
\text { A40 } \\
\text { A42 }\end{array}$ & $\begin{array}{l}\text { A30 } \\
\text { A40 }\end{array}$ & $\begin{array}{l}\text { A23 } \\
\text { A40 } \\
\text { A42 }\end{array}$ & $\begin{array}{l}\text { A23 } \\
\text { A30 } \\
\text { A42 }\end{array}$ & \\
\hline 4 & 3 & & $\begin{array}{l}\text { A12 } \\
\text { A15 } \\
\text { A27 }\end{array}$ & & & A15 & \\
\hline
\end{tabular}

Fonte: Dados do estudo.

As produções totalmente erradas acumulam também diversos tipos de erros. Dada a forma de escrita simbólica sem sentido matemático, essas produções foram associadas a $E D s$ de convicção externa ligados ao simbolismo não referencial. 
Ainda no nível 0, encontram-se treze produções que usaram argumentos de convicção externa não válidos no universo $(\mathbb{C})$ da tarefa. A classificação dos EDs em causa está relacionada aos erros cometidos, que foram de todos os tipos, mas em particular do tipo ER.

Nas duas produções que recorrem a EDs empírico indutivos, o erro de tipo ED está diretamente associado ao tipo de esquema usado. 0 erro EN presente em A14 também se relaciona a esse tipo de esquema ao utilizar a mesma notação $(z$ e $w$ ) para complexos arbitrários e para complexos concretos.

Nos casos dos EDs dedutivos, os erros cometidos não condicionam o esquema utilizado, mas o nível em que se enquadram (3 e 4). As produções com esse tipo de esquema, níveis 4 e 5, apresentam, respectivamente, menor número de tipos de erros ou não os têm (nos níveis 5 e 6 não são aceitos erros).

\section{Discussão}

As estratégias de resolução mais escolhidas pelos alunos foram a transitividade da igualdade e a equivalência lógica, com igual número de ocorrências e de forma expressiva em comparação às restantes estratégias usadas. 0 recurso a exemplos foi uma delas. Só foram identificadas duas ocorrências ( 5 por cento), nível 1, em que os alunos consideraram números complexos concretos, o que não corrobora estudos existentes (BUCHBINDER; ZASLAVSKY, 2019; CHAZAN; LUEKE, 2009; HEALY; HOYLES, 2000; RODRIGUES, 2009). Uma possível explicação pode passar pelas aulas da uc nas quais se tentou trabalhar a demonstração. Como Kanellos, Nardi e Biza (2018), encontraram-se produções que combinam mais de uma categoria de Harel e Sowder (1998). Uma das produções, com ED empírico, apresenta também algumas inferências que podem ser consideradas como ED dedutivo, nível 3.

As categorias de Harel e Sowder (1998) nas quais se enquadram a maioria dos EDs analisados são de convicção externa (23) e dedutivo (18). Os níveis de Lee (2016) permitiram destrinçar particularidades entre as 41 produções. No nível 0 , há casos (6) em que os EDs são quase inexistentes, o que dificultaria a inclusão em alguma das subcategorias de Harel e Sowder (1998). Talvez por se tratar de alunos do ensino superior, as subcategorias autoritário e ritual da categoria convicção externa não foram identificadas, tendo a subcategoria simbólico não referencial quatro ocorrências.

Treze produções evidenciaram o recurso a argumentos de convicção externa, num sentido que não encontramos em Harel e Sowder (1998) e Lee (2016). Dado o nível de escolaridade destes alunos, eles já tiveram contato com tarefas cuja resolução exigia EDs dedutivos, estruturalmente semelhantes aos passiveis de serem usados na resolução da tarefa. A diferença crucial é a mudança do contexto matemático da tarefa, os familiares aos alunos eram em $\mathbb{R}$ e o solicitado era em $\mathbb{C}$. Os alunos resolveram a tarefa como se estivessem em $\mathbb{R}$, não discernindo a adequação ou não dessa atitude, que por isso não se reflete no sentido de utilizar apenas o que é extensível a $\mathbb{C}$. É ainda importante mencionar que esses alunos pertencem ao grupo dos que mantiveram as variáveis $z$ e $w$, e usaram-nas como se representassem números reais. Entende-se que estes casos evidenciam EDs de convicção 
externa, mas não se enquadram nas subcategorias indicadas em Harel e Sowder (1998), sendo necessária a criação de uma nova subcategoria denominada não válidos no universo.

No último grupo de produções há evidência do uso de EDs dedutivos, mas com validade nula, dado que em termos lógicos os alunos partiram de premissas falsas. Assim, também nesses casos, há combinação de categorias (KANELLOS; NARDI; BIZA, 2018). 0 fato de não aparecer o nível 2 (LEE, 2016), relacionado ao uso estratégico de exemplos, pode prender-se ao fato de a tarefa associada ao estudo ser de demonstração para uma proposição que é dito ter valor lógico verdade. Quanto aos EDs dedutivos, foram encontradas produções que se distribuem pelos níveis 3, 4 e 5 de Lee (2016), 78 por cento no nível mais baixo. Apenas uma produção estava correta, mas ainda não usava representações formais. Ou seja, apenas um aluno se encontra na fase 4 (LEE, 2016).

Os EDs dedutivos ainda apresentam falhas ao nível da dedução lógica, havendo lacunas na compreensão dos conceitos de igualdade, equivalência e implicação. As falhas na validade das deduções prendem-se a dois aspectos. Um, designado (falta de) discernimento, que foi considerado um nível anterior ao nível 3 (LEE, 2016), dentro da fase 3. Está relacionado à compreensão da tarefa proposta, a identificação do seu contexto matemático, das hipóteses e da tese, bem como com a procura de conhecimentos prévios mobilizáveis para encontrar a solução (POLYA, 2003). Mas, principalmente, com as características do raciocínio lógico dos alunos, por exemplo, o fato de que, partindo de premissas falsas e usando lógica matemática, é possível provar qualquer absurdo, pois não é a lógica que detecta se as premissas são falsas, é quem usa a lógica que tem de discernir se o que está empregando é ou não verdadeiro. 0 outro aspecto prende-se aos erros cometidos.

A maioria dos erros é dos tipos EL e EM, respectivamente, relacionados com a compreensão da linearidade de uma função e do módulo de um número complexo. As frequências dessas categorias diferem apenas em duas unidades, sendo expressivas quando comparadas às frequências de outras categorias de erros. Contudo, a categoria dominante EL, cujo erro com maior número de ocorrências consiste em considerar o módulo da soma de dois números complexos igual à soma dos módulos desses complexos, não inclui o erro dominante na totalidade das produções. É a categoria EM, não dominante, que o inclui: considerar a igualdade de números complexos como consequente da igualdade de módulos desses complexos. 0 segundo erro mais frequente pertence à categoria, não dominante, ER: considerar que o quadrado do módulo de um número complexo é igual ao quadrado desse complexo.

Os erros da categoria EL emergem da aplicação de pelo menos uma das duas condições de linearidade a funções de variável complexa (função módulo, dada por $z \longmapsto|z|$, função quadrado, dada por $Z \longmapsto Z^{2}$, e suas composições) ou de variável real (função raiz quadrada, dada por $x \longmapsto \sqrt{ } x$ ) que não são lineares. Esses erros podem ser uma ilusão da linearidade, como no contexto de ampliação e redução de figuras geométricas planas e sólidos (DE BOCK et al., 2007). Concretamente, em erros que resultam da aplicação da segunda condição de linearidade (imagem de um múltiplo escalar de um vetor igual ao escalar pela imagem desse vetor) são indicados fatores explicativos para a utilização da proporcionalidade quando não for adequado: raciocínio intuitivo e não analítico; experiências escolares; e conteúdos específicos do programa. 
Segundo estudos feitos em diversos anos de escolaridade (BAGNI, 2000), alunos principiantes tendem a considerar lineares todas as funções. Para muitos que nem conhecem a noção de função linear na álgebra, como parte dos alunos do estudo ao resolverem a tarefa, o sentido de considerar não é pensar que as funções são lineares. De fato, o sentido é o do modo operacional (MARKOVITS; EYLON; BUCKHEIMER, 1986 apud BAGNI, 2000) - aplicar as condições de linearidade de uma função sem pensar na noção. Alguns autores falam em obstáculos afetivos, que podem ser difíceis de ultrapassar (D’AMORE; MARTINI, 1997 apud BAGNI, 2000), quando os alunos, tendo utilizado anteriormente uma regra simples e, não conhecendo outra, a estendem incorretamente por a associarem ao sucesso.

Os erros da categoria EM estão relacionados ao conceito de módulo de um número complexo e resultam de: consequentes ou equivalências a partir de igualdades que envolvem módulos de números complexos; expressões para o módulo de um número complexo, ou para o quadrado deste; e considerar o módulo de um número complexo não pertencente a $\mathbb{R}_{0}^{+}$. Na segunda proveniência, com duas ocorrências na produção de um aluno, embora pouco expressivas em número, podem estar relacionadas com um conceito imagem de números complexos: números 2-dimensionais (NORDLANDER; NORDLANDER, 2012). Com efeito, as duas parcelas na expressão em módulo, cada uma delas sendo um número complexo $(z, w)$ mas sem a escrita da unidade imaginária, parecem ser consideradas como a parte real e a parte imaginária de um número complexo.

A categoria EA é a terceira com maior número de erros, ligeiramente superior a metade das ocorrências em cada uma das categorias EL e EM, relacionados à aritmética dos números complexos. Os erros em EA, exceto dois, provêm de quadrados de expressões. Em algumas das ocorrências, e numa das exceções, a prioridade das operações não foi atendida (ACCARD0; KUDER, 2017; RUSHTON, 2014) e, em particular, ocorreu uma incorreção na aplicação da distributividade da multiplicação em relação à adição de complexos. Esses erros operacionais têm como causa frequente o nervosismo (TORRE, 1993). Noutra exceção, surge um erro de simplificação presenciado em anos anteriores ao ensino superior: expressão igual à mesma dividida pelo máximo divisor comum dos coeficientes dos termos, parecendo coincidir com as noções de expressão e equação (RUSHTON, 2014).

$\mathrm{Na}$ categoria ER, com um número de ocorrências que só difere em três da categoria EA, estão os erros relacionados à extensão de (quase) propriedades dos números reais. Os erros em ER são as versões complexas de conhecidas (quase) propriedades dos números reais, envolvendo quadrados e módulos de números complexos e suas relações. Esses erros podem ser vistos como uma tentativa de extensão de uma regra familiar que, para alunos que não encontram regras específicas para uma tarefa - tecnicamente, segundo Bagni (2000), por fraqueza algébrica -, pode parecer natural e confortável. 0 mesmo processo pode ser seguido por um matemático, mas com uma diferença relevante que consiste, após a tentativa, num processo regulatório de questionamento acerca da validade no contexto específico.

Com frequência igual à da categoria ER, os erros de tipo EN estão relacionados à compreensão da notação matemática. As ocorrências em EN resultam de incorreções de escrita, em linguagem algébrica ou em linguagem verbal. Por coexistirem com notação correta em situações similares da mesma produção, podem ser consideradas erros mecânicos ou lapsos (troca de sinal, de letras, de palavras, entre outros) que, segundo Torre (1993), são mais frequentes em alunos que gostam de tentar novos caminhos para 
resolver uma tarefa, sendo comuns em alunos hiperativos. Salientamos duas ocorrências de falta de parêntesis na representação do simétrico de um número complexo que, embora pouco expressivas em número, traduzem um erro frequente em anos anteriores ao ensino superior e ligado à prioridade das operações (ACCARDO; KUDER, 2017).

0 tipo de erro com menor frequência é o ED, relacionado à compreensão da demonstração em matemática, com uma diferença de seis ocorrências das categorias ER e EN. As ocorrências de erro do tipo ED provêm maioritariamente de formas de demonstração, ligadas a duas estratégias lógicas, incorretamente utilizadas. Embora os estudos (BUCHBINDER; ZASLAVSKY, 2019; CHAZAN; LUEKE, 2009; HEALY; HOYLES, 2000; RODRIGUES, 2009) apontem uma tendência para a utilização de casos particulares para demonstrar, o presente trabalho não a corrobora por este erro do tipo ED ser residual. A possível explicação das aulas, indicada no começo desta seção, pode ainda justificar a menor frequência da categoria ED. De fato, apesar de não serem capazes de construir uma, os alunos poderiam ter uma expectativa clara de uma demonstração válida (STYLIANIDES; STYLIANIDES, 2009 apud LEE, 2016).

Não se reconhece nenhuma tendência na distribuição dos diversos tipos de erros identificados relativamente a EDs específicos, parcial ou totalmente incorretas, que os alunos elaboraram nas produções em resposta à tarefa (Figura 1). No entanto, alguns tipos de erros (EM, ER, EN) condicionam mais EDs de convicção externa. Esses tipos de erros estão ligados à compreensão dos conceitos, da sua representação e do universo matemático da tarefa. Os erros do tipo ED são também um obstáculo à consecução de EDs dedutivos, agora ligados à compreensão do que é uma demonstração em matemática.

A notação $z$ e $w$ para representar números complexos genéricos, ainda que correta, contribuiu para os alunos esquecerem que se tratavam de complexos, assumindo-os como reais. Se fossem analisados no universo matemático que os alunos consideraram ( $\mathbb{R})$, os EDs poderiam ser considerados dedutivos. Sendo alunos do ensino superior, é como se utilizassem EDs em níveis (LEE, 2006) diferentes consoante o universo matemático dedutivos em contextos com que estão familiarizados e de convicção externa em novos contextos. Isso não corrobora a ideia de Lee (2016), sobre a classificação de Harel e Sowder, de que a demonstração matemática dos alunos progride de uma orientação indutiva para uma dedutiva, mas sugere uma nova.

Atendendo às categorizações de Harel e Sowder (1998), cujas categorias representam níveis cognitivos diferentes do desenvolvimento matemático, e de Lee (2016), visando perceber certas sutilezas cognitivas, seria expectável a diminuição do número de tipos de erros à medida que aumenta o nível do ED. 0 nível 4 corresponde claramente ao menor número de tipos de erros, mas a expectativa não se concretiza nos níveis 0 a 3 , particularmente no nível 1 para o 3. Apesar dos EDs dedutivos, no nível 3 presencia-se um grande número de tipos de erros, comparável ao que se nota no nível 0 , algo também observado por Selden e Selden (1987) sem a especificação de níveis.

\section{Considerações finais}

De modo a promover a aprendizagem dos alunos, o primeiro passo no tratamento didático do erro deve consistir no erro ser observável para os professores. 0 segundo passo 
é tornar o erro observável e superável para os alunos, exigindo uma reflexão do professor sobre a (remodelação da) sua prática letiva. Neste trabalho, por meio de produções de alunos do ensino superior para uma tarefa de demonstração de um caso particular da identidade do paralelogramo, foi possível trazer alguma luz quanto ao primeiro passo no tópico números complexos. Como os erros dos alunos devem provocar conflitos cognitivos ao professor, que o levem a questionar a natureza do erro, contribuiu-se também para a reflexão necessária no segundo passo. Em seguida, detalham-se as conclusões do trabalho e apresentamse as considerações finais, nomeadamente quanto aos contributos novos do estudo.

Os esquemas de demonstração nas produções dos alunos foram classificados partindo das categorias de Harel e Sowder (1998) e das fases de Lee (2016), mas, ao contrário de outros estudos, apenas foram registradas duas ocorrências de EDs empíricos. Os alunos utilizaram, principalmente, EDs de convicção externa e dedutivos. Os de convicção externa, majoritariamente, numa subcategoria nova designada (argumentos de convicção externa) não válidos no universo, cuja característica diferenciadora é a não adaptação à mudança de contexto matemático. As subcategorias autoritário e ritual não foram identificadas e o número de ocorrências na subcategoria simbólico não referencial foi residual. Os EDs dedutivos ainda com falhas na dedução lógica apresentam inconsistências nos conceitos de igualdade, equivalência e implicação, com consequências na validade das deduções.

Os resultados encontrados apontam para a existência, na fase 3 de Lee (2016), de um nível novo, prévio ao 3, caracterizado por: discernimento incipiente da compreensão da tarefa, do contexto matemático, das hipóteses e da tese, e dos conhecimentos prévios a mobilizar. 0 aspecto do contexto matemático emerge em $E D$ incluído nesse novo nível criado, com a presença natural de erros que resultam da extensão de (quase) propriedades dos números reais. Essas ocorrências remetem para o conceito imagem de números 2-dimensionais de Nordlander e Nordlander (2012), que foi identificado por meio de números complexos concretos. Neste estudo, estende-se a identificação do mencionado conceito imagem, por meio de números complexos quaisquer denotados por $z$. Concretamente, nem as partes real e imaginária, nem a unidade imaginária, estão visíveis com essa notação.

Identificaram-se erros relacionados com: a compreensão do conceito de linearidade de uma função; a compreensão do conceito de módulo de um número complexo; a aritmética dos números complexos; a extensão de (quase) propriedades dos números reais; a notação matemática; e a compreensão do conceito de demonstração. Foram apresentadas ainda possíveis explicações para os erros, em sua maioria relacionados com a compreensão dos conceitos de linearidade de uma função e de módulo de um número complexo. No primeiro caso, o erro mais frequente consiste em considerar o módulo da soma de dois números complexos igual à soma dos módulos desses complexos. No entanto, globalmente, o erro mais frequente diz respeito ao segundo caso: igualdade de números complexos como consequente da igualdade de módulos desses complexos.

Também bastante frequente é o erro de considerar versões complexas de conhecidas (quase) propriedades dos números reais, envolvendo quadrados e módulos de números complexos, associado a ED de convicção externa na nova subcategoria não válidos no universo. Os EDs mais utilizados e os erros mais cometidos apontam no sentido de que a demonstração matemática pode não progredir de uma orientação indutiva para uma orientação dedutiva, como defendia Lee (2016) contrariamente a Harel e Sowder 
(1998), pois os alunos do estudo manifestaram EDs dedutivos em contextos familiares (números reais), retrocedendo nos níveis de Lee num contexto matemático novo (números complexos). Para além das referidas associação e indicação, não foi descoberta uma relação propriamente significativa entre os EDs usados e os erros cometidos.

Dos resultados deste trabalho, cuja divulgação pode dar pistas para a prática letiva de professores do ensino secundário e do ensino superior, emerge o desafio criativo de aproveitar a análise realizada para tornar o erro observável e superável para outros alunos. De fato, dos EDs e dos erros identificados neste estudo, obteve-se material com potencial para gerar uma estratégia didática. Duas formas possiveis podem gerar discussão: a partir de dúvidas em sessões de estudo (CURY, 2007); e a partir de questões conceituais construídas com erros (BEITES; ROMANO, 2014). A título de exemplo, para discussão em ambiente de aprendizagem pelos pares, elaborou-se uma questão conceitual (Figura 23) com o erro que possui a maior frequência (a), um erro com uma só ocorrência (b) e, no sentido da validade num certo universo matemático, uma conhecida propriedade dos números reais (c).

Figura 23 - Proposta de uma questão conceitual

Sejam $z, w \in \mathbb{C}$, quaisquer. Qual é a opção correta?

a) $|z|=|w| \Rightarrow z=w$

b) $|z|=|w| \Rightarrow z=-w$

c) $|z|=|w| \Rightarrow z=w \mathrm{~V} z=-w$

d) nenhuma das anteriores

Fonte: Elaboração própria com os dados do estudo.

\section{Referências}

ACCARDO, Amy L.; KUDER, S. Jay. Monitoring student learning in Algebra. Mathematics Teaching in the Middle School, Reston, v. 22, n. 6, p. 352-359, 2017.

ARCE, Matías; CONEJO, Laura; ORTEGA, Tomás. Análisis de los procesos de justificación y generalización de la fórmula del área del rectángulo por alumnos del grado de educación primaria. Profesorado, Granada, v. 18, n. 2, p. 209-227, 2014.

BAGNI, Giorgio T. "Simple" rules and general rules in some High School students' mistakes. Journal für Mathematik-Didaktik, New York, v. 21, n. 2, p. 124-138, 2000.

BARDIN, Laurence. Análise de conteúdo. Lisboa: Ed. 70, 2016.

BARROS, Paula Maria; FERNANDES, José António; ARAÚJJ, Claúdia Mendes. Perspetivas dos alunos sobre o erro como estratégia de aprendizagem. In: SEMINÁRIO DE INVESTIGAÇÃO EM EDUCAÇÃO MATEMÁTICA, 27., 2016, Porto. Atas [...]. Porto: Associação de Professores de Matemática, 2016. p. 119-131. 
BEITES, Patrícia Damas; BRANCO, Maria Luísa F. R.; COSTA, Maria Cecília R. P. P. da. Esquemas de demonstração para proposições de álgebra linear com valor lógico verdade. Revista Latinoamericana de Investigación en Matemática Educativa, Ciudad de México, v. 23, n. 1, p. 37-78, 2020.

BEITES, Patrícia Damas; ROMANO, Ana. Nestas aulas é melhor falar do que estar calado! Educação e Matemática, Lisboa, n. 129, p. 13-16, 2014.

BORASI, Rafaella. Capitalizing on errors as "springboards for inquiry": a teaching experiment. Journal for Research in Mathematics Education, Reston, v. 25, n. 2, p. 166-208, 1994.

BUCHBINDER, Orly; ZASLAVSKY, Orit. Strengths and inconsistencies in students' understanding of the roles of examples in proving. The Journal of Mathematical Behavior, Amsterdam, v. 53, p. 129-147, 2019.

CHAZAN, Daniel; LUEKE, Michael. Exploring relationships between disciplinary knowledge and school mathematics: implications for understanding the place of reasoning and proof in school mathematics. In: STYLIANOU, Despina; BLANTON, Maria; KNUTH, Eric (ed.). Teaching and learning proof across the grades: a K-16 perspective. New York: Routledge, 2009. p. 21-39.

CURY, Helena Noronha. Análise de erros: 0 que podemos aprender com as respostas dos alunos. Belo Horizonte: Autêntica, 2007.

DE BOCK, Dirk et al. The illusion of linearity: from analysis to improvement. New York: Springer, 2007.

GUIMARÃES, Sandra Carina Machado. Estudar e aprender no ensino superior: a experiência do aluno novel de engenharia informática. 2016. Tese (Doutoramento em Educação) - Universidade da Beira Interior, Covilhã, Portugal.

HAREL, Guershon; SOWDER, Larry. Students' proof schemes: results from exploratory studies. In: SCHOENFELD, Alan H.; KAPUT, Jim; DUBINSKY, Ed (ed.). Research in collegiate mathematics education. v. 3. Providence: American Mathematical Society, 1998. p. 234-283.

HAREL, Guershon; SOWDER, Larry. Toward comprehensive perspectives on the learning and teaching of proof. In: LESTER JR., Frank K. (ed.). Second handbook of research on mathematics teaching and learning. Charlotte: NCTM, 2007. p. 805-842.

HEALY, Lulu; HOYLES, Celia. A study of proof conceptions in Algebra. Journal for Research in Mathematics Education, Reston, v. 31, n. 4, p. 396-428, 2000.

KANELLOS, Ioannis; NARDI, Elena; BIZA, Irene. Proof schemes combined: mapping secondary students' multi-faceted and evolving first encounters with mathematical proof. Mathematical Thinking and Learning, Abingdon, v. 20, n. 4, p. 277-294, 2018.

LANNIN, John K.; BARKER, David D.; TOWNSEND, Brian E. How students view the general nature of their errors. Educational Studies in Mathematics, New York, v. 66, n. 1, p. 43-59, 2007.

LEE, Kosze. Students' proof schemes for mathematical proving and disproving of propositions. The Journal of Mathematical Behavior, Amsterdam, v. 41, p. 26-44, 2016. 
MIYAZAKI, Mikio; FUJITA, Taro; JONES, Keith. Students' understanding of the structure of deductive proof. Educational Studies in Mathematics, New York, v. 94, n. 2, p. 223-239, 2017.

NORDLANDER, Maria Cortas; NORDLANDER, Edvard. On the concept image of complex numbers. International Journal of Mathematical Education in Science and Technology, Abingdon, v. 43, n. 5, p. 627-641, 2012.

PINTO, Neuza Bertoni. 0 erro como estratégia didática no ensino da matemática elementar. 1998. Tese (Doutorado em Educação) - Universidade de São Paulo, São Paulo, 1998.

POLYA, George. Como resolver problemas. Lisboa: Gradiva, 2003.

RECIO, Angel M.; GODINO, Juan D. Institutional and personal meanings of mathematical proof. Educational Studies in Mathematics, New York, v. 48, n. 1, p. 83-99, 2001.

RICO, Luis. Errores y dificultades en el aprendizaje de las matemáticas. In: KILPATRICK, Jeremy; GÓMEZ, Pedro; RICO, Luis (ed.). Educación matemática. México, DC: Iberoamericana, 1998. p. 69-108.

RODRIGUES, Margarida. A demonstração na prática social da aula de matemática. 2009. Tese (Doutoramento em Educação) - Universidade de Lisboa, Lisboa, 2009.

RUSHTON, Nicky. Common errors in mathematics. Research Matters, Cambridge, n. 17, p. 8-17, 2014.

SELDEN, Annie; SELDEN, John. Errors and misconceptions in college level theorem proving. In: INTERNATIONAL SEMINAR ON MISCONCEPTIONS AND EDUCATIONAL STRATEGIES IN SCIENCE AND MATHEMATICS, 2., 1987, Ithaca. Proceedings [... ]. Ithaca: Cornell University, 1987. p. 457-470.

TORRE, Saturnino de la. Aprender de los errores: el tratamiento didáctico de los errores como estrategia de innovación. Madrid: Escuela Española, 1993.

Recebido em: 25.03.2020

Revisado em: 29.04.2020

Aprovado em: 30.06.2020

Patrícia Damas Beites é doutora em matemática e professora auxiliar do Departamento de Matemática da Universidade da Beira Interior. É investigadora (membro integrado) do Centro de Matemática e Aplicações (CMA-UBI), com interesses de investigação em álgebra, predominantemente não associativa, e em educação matemática, com ênfase no ensino superior.

Maria Luísa Branco é doutorada e agregada em educação e professora associada do Departamento de Psicologia e Educação da Universidade da Beira Interior, onde ensina e investiga no âmbito das ciências da educação e das metodologias qualitativas. É investigadora (membro integrado) do Centro de Investigação em Educação e Psicologia (CIEP), da Universidade de Évora. 
Cecília Costa é doutora em matemática e agregada em didática de ciências e tecnologia, professora associada da Universidade de Trás-0s-Montes e Alto Douro, membro integrado do Centro de Investigação Didática e Tecnologia na Formação de Formadores (CIDTFF). 